$1-1-1953$

\title{
Cooperative nutritional status studies in the Northeast Region.
}

M.J. Babcock

Follow this and additional works at: https://researchrepository.wvu.edu/ wv_agricultural_and_forestry_experiment_station_bulletins

\section{Digital Commons Citation}

Babcock, M. J., "Cooperative nutritional status studies in the Northeast Region." (1953). West Virginia Agricultural and Forestry Experiment Station Bulletins. 361T.

https://researchrepository.wvu.edu/wv_agricultural_and_forestry_experiment_station_bulletins/628 @ WVU. It has been accepted for inclusion in West Virginia Agricultural and Forestry Experiment Station Bulletins by an authorized administrator of The Research Repository @ WVU. For more information, please contact ian.harmon@mail.wvu.edu. 

(1) Sil

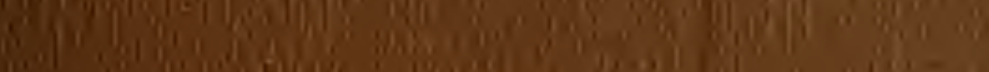

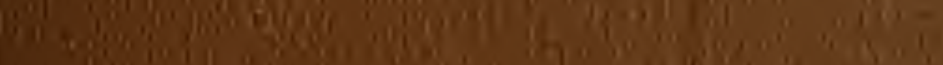
[1,

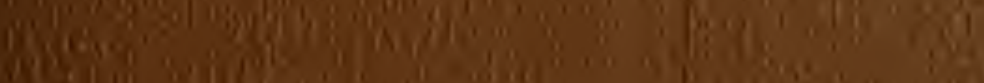

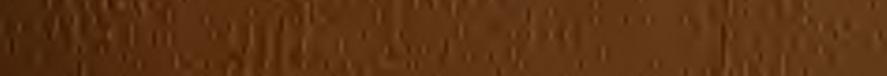

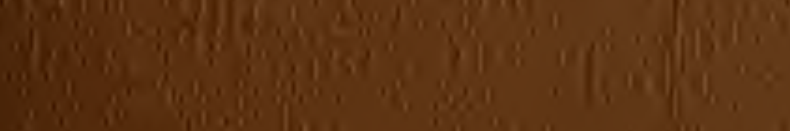

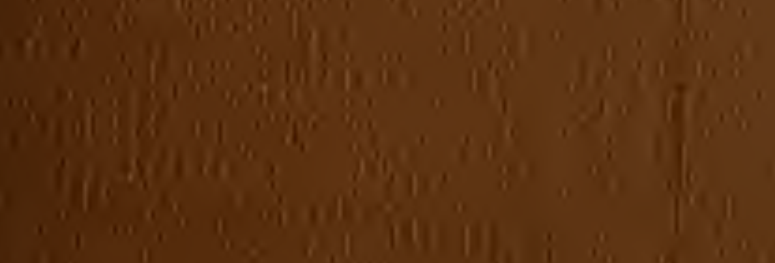

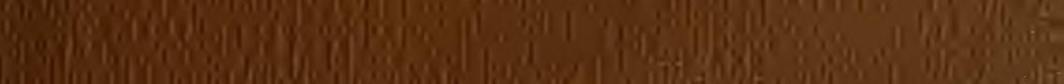
Il,

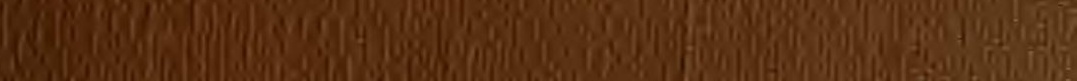

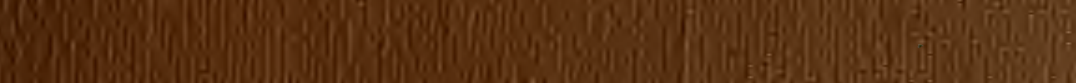



WEST VIRGINIA AGRICULTURAL EXPERIMENT STATION WEST VIRGINIA UNIVERSITY

MORGANTOWN, WEST VIRGINIA

JUNE, 1953

Bulletin 36IT

\section{Cooperative Nutritional Status Studies}

\section{in the Northeast Region}

VI. Correlations

Published for the State Agricultural Experiment Stations of Maine, Massachusetts, New Jersey, New York, Rhode Island, and West Virginia. The Research was conducted cooperatively by these agencies and was supported in part by regional funds. 
Digitized by the Internet Archive in 2010 with funding from

Lyrasis Members and Sloan Foundation 


\section{Cooperative Nutritional Status Studies in the Northeast Region}

VI. Correlations

By

M. J. Babcock, ${ }^{1}$ Mary M. Clayton, ${ }^{2}$ Walter D. Foster, ${ }^{3}$ Mary E. Lojkin, ${ }^{4}$ Ruth E. Tucker, ${ }^{5}$ A. $\mathrm{H}$. VanLandingham, ${ }^{3}$ and Charlotte M. Young. ${ }^{6}$

1. New Jersey Agricultural Experiment Station

2. Maine Agricultural Experiment Station

3. West Virginia Agricultural Experiment Station

4. Massachusetts Agricultural Experiment Station

5. Rhode Island Agricultural Experiment Station

6. New York Agricultural Experiment Station, Cornell University and the School of Nutrition

Published for the Agricultural Experiment Stations of Maine, Massachusetts, New Jersey, New York, Rhode Island, and West Virginia. The research was conducted cooperatively by these agencies and was supported in part by regional funds. 


\section{COOPERATING AGENCIES AND PERSONNEL}

Maine Agricultural Experiment Station, University of Maine, Orono.

Massachusetts Agricultural Experiment Station, University of Massachusetts, Amherst.

New Jersey Agricultural Experiment Station, Rutgers University, New Brunswick.

New York, Cornell University Agricultural Experiment Station and the School of Nutrition, Cornell University, Ithaca.

Rhode Island Agricultural Experiment Station, University of Rhode Island, Kingston.

West Virginia Agricultural Experiment Station, West Virginia University, Morgantown.

\section{ADMINISTRATIVE ADVISER}

Mason H. Campbell. Rhode Island Agricultural Experiment Station, University of Rhode Island, Kingston.

\section{TECHNICAL COMMITTEE}

Maine: Mary M. Clayton.

Massachusetts: Anne W. Wertz. (Alternate: Mary E. Lojkin.)

New Jersey: M. J. Babcock.

New York: Charlotte M. Young. (Alternate: Betty F. Steele.)

Harold H. Williams, Chairman.

Rhode Island: Ruth E. Tucker.

West Virginia: A. H. VanLandingham. (Succeeded by: Walter R. Lewis,) Walter D. Foster (ex officio).

The Technical Committee assumed the functions of the Statistical and Publications Committees.

\section{DIETARY SUBCOMMITTEE}

Maine: Mary M. Clayton.

Massachusetts: Gladys Hagan Murphy.

New York: Charlotte M. Young. Chairman. (Alternate: Betty F. Steele.)

New Jersey: Helen N. Church. (Alternate: Lorraine O. Gates.)

Rhode Island: Ruth E. Tucker.

West Virginia: Faith W. Chalmers.

\section{CHEMICAL SUBCOMMITTEE}

Maine: Mary M. Clayton. Chairman.

Massachusetts: Anne W. Wertz. (Alternate: Mary E. Lojkin.)

New York: H. H. Williams.

New Jersey: M. J. Babcock.

Rhode Island: Ruth E. Tucker.

West Virginia: Sam Stregevesky. 


\section{CLINICAL SUBCOMMITTEE}

Maine: Mary M. Clayton.

Massachusetts: Anne W. Wertz. (Alternate: Mary E. Lojkin.)

New York: H. H. Williams.

New Jersey: M. J. Babcock. Chairman.

Rhode Island: Ruth E. Tucker.

West Virginia: J. J. Lawless, M. D.

The Clinical Subcommittee had the consultation and advice of the following: Norman S. Moore, M. D., School of Nutrition, Cornell University, Ithaca, New York; A. Hughes Bryan, M. D., Dept. of Public Health Nutrition, University of North Carolina, Chapel Hill, North Carolina, and Chester A. Newhall, M. D., College of Medicine, University of Vermont, Burlington, Vermont.

\section{BIOMETRICIAN}

Walter D. Foster, West Virginia Agricultural Experiment Station, Morgantown, West Virginia.

\section{COOPERATORS}

Susan B. Merrow. College of Medicine, University of Vermont, Burlington, Vermont.

Milicent Hathaway. Food and Nutrition Division, Agricultural Research Administration, Bureau of Human Nutrition, U. S. Department of Agriculture, Washington 25, D. C.

Georgian Adams, Experiment Station Administrator, U. S. Department of Agriculture, Agricultural Research Administration, Office of Experiment Stations, Washington 25, D. C. 


\section{CONTENTS}

PAGE

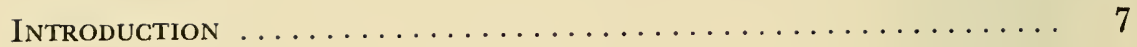

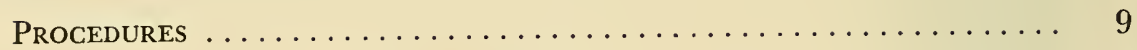

Simple Correlation Coefficients $\ldots \ldots \ldots \ldots \ldots \ldots \ldots \ldots \ldots 9$

Chi-square Test of Contingency $\ldots \ldots \ldots \ldots \ldots \ldots \ldots \ldots .9$

Comparison of Mean Nutrient Levels .............. 11

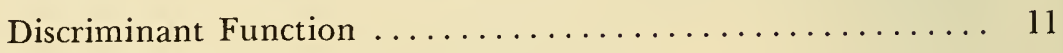

Effect of Nutritional Status on Associations ............ 12

Results ANd Discussion $\ldots \ldots \ldots \ldots \ldots \ldots \ldots \ldots \ldots \ldots \ldots \ldots .13$

Simple Correlation Coefficients ................ 13

Chi-square Test of Contengency $\ldots \ldots \ldots \ldots \ldots \ldots \ldots \ldots, 16$

Comparison of Mean Nutrient Levels .............. 19

Discriminant Function $\ldots \ldots \ldots \ldots \ldots \ldots \ldots \ldots \ldots \ldots \ldots \ldots \ldots \ldots \ldots \ldots$

Effect of Nutritional Status on Associations ............ 25

INTERPRETATION OF RESULTS $\ldots \ldots \ldots \ldots \ldots \ldots \ldots \ldots \ldots \ldots \ldots \ldots \ldots \ldots \ldots \ldots$

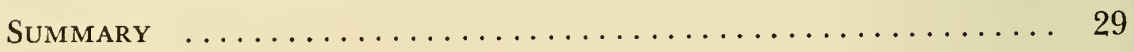

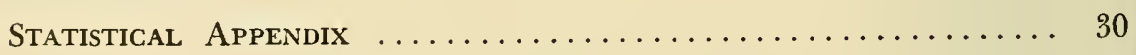

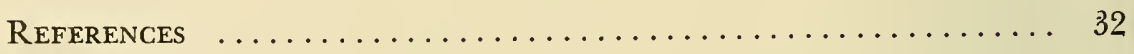

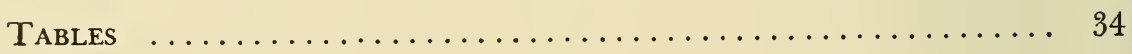




\section{INTRODUCTION}

A knowledge of the nutritional status of various population groups is an essential part of any program to improve the health of a populace. Such knowledge can best be attained from nutritional surveys that include dietary, chemical, and medical measures of nutritional status. These surveys are, however, expensive, and they frequently yield data that are difficult to interpret. To simplify the survey procedures, and to increase the value of the data collected, it is necessary to obtain a better understanding of the complex relationships between dietary intake, biochemical processes, and physical signs. The present study is a step in this direction.

Correlations between results obtained by dietary, chemical, and clinical methods for estimating nutritional status have been reviewed recently (Sinclair, 1948; Putnam, et al, 1949; National Research Council, 1949). These authors indicate that low correlations may be due to experimental errors, to incorrect interpretation of the data, or to a combination of these factors.

The types and magnitudes of experimental errors involved in the collection of dietary, chemical and clinical data have been discussed elsewhere (National Research Council, 1949; Babcock, et al, 1952; Young, et al, 1952; Clayton, et al, 1953). The effect of these errors on methods employed in correlation analysis tends, on the average, to depress the degree of association or to mask it entirely, so that underestimation of relationships is very likely. On the other hand, gross errors are capable of causing an entirely fictitious result to appear.

Incorrect interpretation may result from incomplete understanding of the quantitative relationships between dietary intake, body chemistry, and gross physical changes during the development and recession of chronic multiple deficiences. The understanding of these relationships is made particularly difficult by several factors characteristic of subjects studied in their usual environment. Of primary importance is the fact that the quantity and quality of nutrients in the diet varies from meal to meal and from day to day. The length of time required for these dietary fluctuations to be reflected in tissue levels and gross physical changes varies with the nutrient, with the individual, and with conditioning factors. It also has been pointed out (Pett, 1945; Darby, 1947; National Research Council, 1949) that individual variations which place a particular subject in the low end of a frequency distribution curve for blood levels do not necessarily place him in the corresponding part of the frequency distribution curve for clinical signs. Consequently, 
high correlations cannot be expected within the range of normal individual variations. Also, at high levels of nutrient intake, the tendency for the body to store; destroy, or excrete excess nutrients, and the general absence of gross lesions may prevent high correlations of blood and physical findings with dietary intake. Higher correlations are to be expected, therefore, from subjects whose nutritional status ranges from very poor to fair. Although the data presented in this paper were obtained, for the most part, from subjects whose nutritional status was generally fair to good, an attempt was made, in one phase of the analysis, to compare certain correlations obtained at different levels of nutritional status.

This report is the result of work done in Nutritional Status Project NE-4, conducted cooperatively by agricultural experiment stations of the Northeast Region, under the provisions of the Research and Marketing Act of 1946. The objective of the project was the correlation of the results of dietary surveys, biochemical studies, and medical examinations as measures of nutritional status. The data presented here give the measures of those correlations found for various population groups in the region. The population groups studied and the minimum numbers of subjects who provided data for the correlation studies were as follows:

Maine
Massachusetts
New Jersey
New York
Rhode Island
West Virginia

201 junior high school students

74 pregnant women

509 male industrial workers

355 school children

214 high school and college students

206 college students

More detailed descriptions of the populations sampled are given elsewhere (Babcock, et al, 1952).

The techniques used in the collection of the dietary, chemical, and clinical data have been described (Northeast Region, 1951). Every effort was made to use the same methods throughout the project. The findings of the individual measures of nutritional status have been reported separately (Babcock, et al, 1952; Tucker, et al, 1952; Clayton, et al, 1953).

Although two kinds of dietary data were available, diet histories and seven-day diet records (Northeast Region, 1951), it was not feasible to make correlation studies with both types of data. Accordingly, either the history or record was used from each experiment station, depending on which was available from the larger number of subjects. The data presented here utilized diet histories from New Jersey and seven-day diet records from all other states. Subjects who consumed vitamin supple- 
ments were eliminated from the dietary correlation studies for all stations, except Massachusetts. Since it is common practice for pregnant women to take vitamin supplements, the nutrients consumed in supplement form were added to the dietary values for that group before the correlations were calculated.

\section{PROCEDURES}

In this study it was desired to look for associations between 4 blood constituents, 7 dietary nutrients, and 22 physical signs, and to examine these sets of data separately for each of the six cooperating stations. These associations included: (a) blood constituents with dietary nutrients, (b) blood constituents with physical signs, (c) dietary nutrients with physical signs, and (d) partial and multiple associations of blood constituents and dietary nutrients with individual physical signs. The associations of physical signs with blood constituents and with dietary nutrients could not be computed and expressed directly as correlation coefficients because the physical signs were recorded only in descriptive terms (normal, mild, moderate, or severe) rather than as a range of numerical values. Accordingly, two other statistical procedures were employed to measure these associations. The two procedures used in this initial phase of the study were, first, the chi-square test of contingency, and second, the comparison of mean nutrient levels, using the " $t$ " statistic. In addition to providing estimates of the associations of physical signs with blood constituents and dietary nutrients, these procedures served as a screening operation to determine which of the physical signs, blood constituents, and dietary nutrients should be considered in subsequent and more detailed analyses.

\section{Simple Correlation Coefficients}

Correlations between pairs of blood and dietary data were expressed by simple correlation coefficients. Putnam, et al (1949) found no advantage in correlating blood ascorbic acid with the logarithms of ascorbic acid intakes, despite the fact that logarithms of the intakes gave more symmetrical frequency distribution curves for their data.

\section{Chi-square Test of Contingency}

Subjects from one experiment station at a time were divided into three groups according to the blood level or dietary intake of a given nutrient. The chi-square test of contingency (Appendix A) was then applied to test the hypothesis that each of these three groups had the same incidence rate of a given physical sign. Where differences in the inci- 
dence rates were found of such magnitude that they were not likely $(\mathrm{P} \leqq 0.10)$ to have occurred by chance, the physical sign was tentatively considered to be associated with the nutrient. These tests showed which signs had significant association with each nutrient, but did not indicate the relative magnitude of the associations. To provide information on the relative magnitude of those associations that had been shown to be significant by the chi-square test of contingency, the coefficients of mean square contingency or $\mathrm{C}$ values (Appendix B) were calculated.

The chi-square test of contingency was used to test the associations of 22 physical signs with 4 blood constituents and also with 7 dietary nutrients. Treating the data from the six experiment stations separately, pairwise associations between all possible combinations of every physical sign with every blood and dietary constituent were computed, except where very low incidence rates of a particular sign precluded the use of this test. One physical sign, purpura, mentioned in other reports from this project (Babcock, et al, 1952), was excluded from this analysis because there were too few cases of it to justify statistical treatment. Another physical sign, the general appearance rating, was excluded because of its general nature. Likewise, calories, calcium, and phosphorus were excluded from the dietary data because they probably have little direct relationship with the physical signs and blood constituents reported here. The following definitions were used to classify the groups of subjects in the calculations:

Physical signs-Although the incidence rates of a physical sign were originally reported separately for subjects having that sign in mild, moderate, and severe degrees, these groups were combined into a single group of subjects having the sign, to provide sufficient numbers of subjects for statistical treatment.

Blood constituents-The subjects were divided into three groups, low, middle, and high, on the basis of classifications made by Bessey and Lowry (1947). "Low" blood levels were defined as their "poor" group, "middle" levels as their "fair" group, and "high" levels included both their "good" and "excellent" groups. The blood levels corresponding to these classifications are given in Table 1.

Dietary nutrients--The subjects were classified into three groups on the basis of the proportion of the National Research Council (1948) recommended daily allowance of a nutrient supplied by their diets. If a subject's diet supplied less than 50 per cent of the N.R.C. allowance for his age and sex group, he was classified as having a "low" dietary level of that nutrient, if 50 per cent to 69 per cent he was classified as having a "middle" dietary level, and if 70 per cent or more he was classified as having a "high" dietary level. It was recognized that these percentages of the N.R.C. recommended allowances do not have the same significance 
for different nutrients and for different age and sex groups, but they provide a consistent definition applicable to the various nutrients and population groups included in this study.

\section{Comparison of Mean Nutrient Levels}

As the first step in the calculation of partial and multiple associations of blood constituents and dietary nutrients with individual physical signs, mean nutrient levels were computed for subjects with and without physical signs. These data offered further evidence on the magnitude and significance of differences noted in the chi-square analysis, and provided a further basis for screening associations to be tested by the more detailed analyses. For this comparison the subjects at each experiment station were divided into two groups, those with a particular sign (whether mild, moderate, or severe), and those without it. Mean levels of blood constituents and of dietary nutrients were computed for each group. The differences between the means were tested by the " $t$ " statistic (Appendix G).

These comparisons of mean nutrient levels were made for all associations that had been shown to be significant at the 10 per cent level by the chi-square test wherever the data indicated that more than one nutrient was associated at a station with a physical sign. The latter restriction was made because the comparisons of mean nutrient levels were primarily a screening procedure for the partial and multiple association analyses, as will be described later. In addition, to minimize the chance of overlooking any other possible association, wherever the test of contingency yielded a probability greater than 10 per cent, but showed a tendency for association previously reported in the literature, the association was included in the analysis made for mean nutrient levels. A working list of associations previously reported in the literature (Table 2) was prepared by two physicians, Dr. A. Hughes Bryan and Dr. Chester A. Newhall, consultants for this project, from similar lists published by the American Medical Association (1946) and by Jolliffe, Tisdall, and Cannon (1950).

\section{Discriminant Function}

The previously described analyses have dealt with associations between pairs of measures of nutritional status, without regard to any effects of other factors on the associations of those pairs. Since there was evidence of relationships among blood constituents and dietary nutrients, the discriminant function analysis (Appendix D) was used to adjust for any effects of these relationships on the associations of blood and dietary levels with physical signs. In this analysis the subjects at each 
station were divided qualitatively into two groups, those with a particular physical sign (whether mild, moderate, or severe) and those without it. Then the quantitatively measured blood constituents and dietary nutrients that had previously been shown to be associated with that sign at that station were associated collectively with the sign. This approach showed the association of each nutrient with the sign after the effects of other nutrients had been removed by adjusting the subjects to the same level of those other nutrients.

Since this phase of the analysis was concerned with several nutrients at a time, it was applied only to those physical signs for which two or more nutrients (blood or dietary) had been found to be significant by the comparison of mean nutrient levels. A broad definition of significance (20 per cent level) was used, and in a few cases the analysis also was extended to a corresponding blood or dietary nutrient, the association of which had not previously been statistically significant, to take the greatest advantage of the comprehensive analysis afforded by the discriminant function.

The discriminant function analysis also provided information on the accuracy with which a physical sign could be predicted from a combination of blood and dietary data.

\section{Effect of Nutrifional Status on Associations}

Theoretically, the degree of association between dietary levels, blood levels, and physical signs may be expected to vary with the nutritional status of individuals. For deficient subjects blood levels and physical signs should, theoretically, reflect dietary intakes. With subjects on high planes of nutrition, however, the blood and tissue levels tend to be independent of intake. Above the "requirement" level the tissues approach "saturation" and there usually is a tendency for excess nutrients to be destroyed, excreted, or stored, with the result that there is little correlation with blood levels and physical signs.

Correlations between dietary nutrients, blood constituents, and physical signs may, therefore, be very low at high planes of nutrition. When the population studied includes many well-nourished individuals, as was the case in this study, a preponderant number of subjects may fall in this zone of low correlations. The addition of a large number of subjects with low correlations to a small sample of subjects with high corelations will generally reduce the magnitude of the correlation statistic calculated for the group, whether that statistic be calculated by correlation analysis, by the chi-square test of contingency, or by other methods used in this study. Conversely, if this source of variation is removed by restricting the sample to subjects of relatively low nutri- 
tional status, the magnitude of the correlations may be increased. Front the practical point of view, also, we are usually more interested in the association of these different measures of nutritional status in the borderline deficiency zone of nutrition than in the zone of excess.

To test the theory that the magnitude of these correlations may be affected by nutritional status, the analyses in this study were extended to compare correlations obtained in the borderline deficiency zone with correlations obtained at higher planes of nutrition. For this purpose, nutritional status was arbitrarily rated by the degree of severity of associated physical signs, though it was recognized that clinical evidence alone is not a reliable measure of nutritional status, particularly in borderline deficiency states. Correlation coefficients for the association of blood constituents with corresponding dietary nutrients were calculated for each degree of severity of associated physical signs and compared to see if the magnitude of the correlation coefficients increased with severity of the associated signs. The associated physical signs considered here were those previously selected by the screening procedure for the discriminant function analysis.

Another test of the effect of nutritional status on associations was made in which the blood or dietary level was used as the criterion of nutritional status. The chi-square test of contingency for association of physical signs with blood and dietary nutrients was applied to samples of subjects whose dietary or blood levels indicated that they had low nutritional status, and the magnitudes of the $\mathrm{C}$-values were compared with the corresponding values previously obtained for all subjects.

\section{RESULTS AND DISCUSSION}

\section{Simple Correlation Coefficients}

The correlation coefficients ( $r$ ) between blood constituents and related dietary nutrients, and their significance levels, are given in Table 3. These data show the following associations to be significant for subjects at nearly all stations:

Hemoglobin with dietary protein

Hemoglobin with dietary iron

Blood vitamin A with blood carotene

Blood ascorbic acid with dietary ascorbic acid

For the subjects at four stations the correlation of blood carotene with dietary vitamin A (including carotene) was significant at the 10 per cent level. A significant correlation of blood vitamin A with dietary vitamin A was observed only with pregnant women in Massachusetts. Although these correlation coefficients were all less than 0.5 , the consistency of the 
results from station to station suggest that these associations were common to the several age, sex, and geographic groups studied. It does not necessarily follow, however, that the associations always apply to individual subjects. The scatter diagram in Figure 1 shows, for example,

\section{FIGURE 1. SIMPLE CORRELATION COEFFICIENTS}

Correlation between blood and dietary ascorbic acid in Maine subjects as illustrated by a scatter diagram. $r=.421$. (significant at the $1 \%$ level)

\section{Dietary ascor. \\ bic acid, mg.}

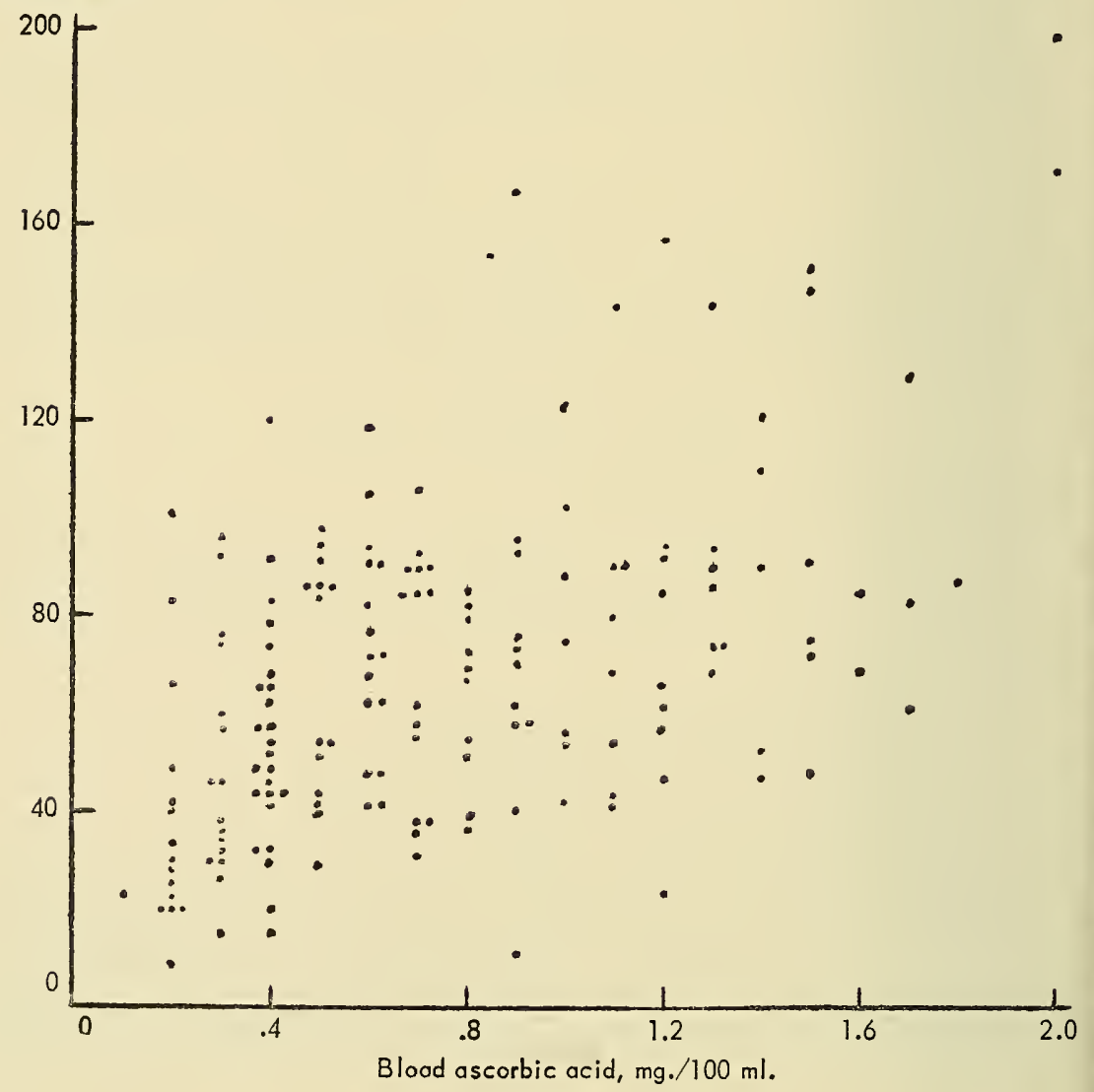


that subjects with high dietary levels of ascorbic acid frequently did not have high blood levels and vice versa. Some of this scattering was probably caused by effects of the previous meal on the blood level. Non-fasting blood samples were used throughout these studies.

Merrow, et al (1952) obtained inconclusive results in a study of relationships between nutrient intake and serum levels of 160 children who had physical signs. When they reduced the relatively wide variation that occurred in dietary and serum values by selecting subjects who had general patterns over a three-year period of high or low dietary or serum values, they were able to demonstrate several significant relationships between corresponding dietary and serum nutrients (ascorbic acid, vitamin $\mathrm{A}$, and carotene). Wide variation usually is encountered in cross-section type surveys, and it probably accounts in large part for the low degree of the associations reported here. Longitudinal studies, though more difficult to carry out, have an advantage in that it is possible to reject from the statistical analysis values that do not appear to be characteristic for an individual.

One significant negative correlation was observed between blood constituents and related dietary nutrients (Table 3). For New Jersey men hemoglobin tended to increase as dietary iron decreased $(\mathrm{r}=-0.171)$. Inspection of the distribution data revealed, however, that this trend was present only at the higher levels of these compounds. Since the majority of the men had iron intakes that exceeded the National Research Council allowance and since nearly all of them had high hemoglobin levels (Table 1 and Clayton, et al, 1953), the low order negative correlation noted did not indicate a nutritional deficiency relationship.

In a study of correlations between blood constituents (ascorbic acid, vitamin A, carotene) and dietary nutrients, Putnam, et al (1949) found that only the relationship between blood ascorbic and dietary ascorbic acid was consistently significant (for 15 of 24 population groups).

A preliminary examination of the data showed a number of blood and dietary associations, in addition to those discussed above, that were significant for subjects at several stations. Correlation coefficients for these associations are given in Table 4. Where significant, these associations may have been due to the tendency for certain nutrients to occur together in some foods, as vitamin A and ascorbic acid in leafy, green vegetables. Also, there may have been a tendency for persons who selected diets good (or poor) in the protective foods to obtain diets good (or poor) in several nutrients simultaneously. Putnam, et al (1949) obtained significant correlation between 7 pairs of blood constituents and between 14 pairs of dietary nutrients. Carroll, et al (1952) found highly significant correlations of dietary protein with intakes of thiamine and riboflavin. 
The highly significant correlation found for subjects at all stations of blood ascorbic acid with blood carotene may indicate a metabolic relationship between these compounds. Interrelationships of ascorbic acid with vitamin A are indicated by the work of Mayer $(1948,1949)$, and Kimble and Gordon (1939).

\section{Chi-square Test of Conşingency}

The statistical hypothesis tested here is that groups of subjects with low, middle, and high blood (or dietary) levels of a nutrient had the same incidence of physical signs. This hypothesis was tested by the chisquare test of contingency in all cases that provided sufficient data to permit a test. Departures from a constant incidence rate, which were significant at the 1 per cent, 5 per cent, and 10 per cent levels are given in Table 5, along with information on the directions and magnitudes of the associations. The direction of an association is listed as positive if the incidence rate of the physical sign increased as the degree of deficiency, indicated by the blood (or dietary) level, increased, and negative if the reverse were true. An illustration of these trends is given in Figure 2. The relative magnitudes of the statistically significant associations are expressed by the coefficients of mean square contingency ( $\mathrm{C}$ values), although it is recognized that these coefficients have several limitations (Appendix B).

Since the significance levels given in Table 5 indicate that there were 1,5 , or 10 chances per hundred that the associations were due to chance sampling, there is greater basis for believing that an association actually exists where several stations found the same association. Positively directed associations that were found to be significant ( 1 per cent, 5 per cent, or 10 per cent level) for subjects at three stations, and the range of their $\mathrm{C}$ values are listed here:

Gingivitis with dietary ascorbic acid $(0.10-0.21)$

Gingivitis with blood carotene $(0.10-0.26)$

Increased vascularity of the bulbar conjunctiva with blood ascorbic acid (0.11)

Positively directed associations that were found to be significant ( 1 per cent, 5 per cent or 10 per cent level) for subjects at two stations and their $\mathrm{C}$ values were as follows:

Acne (facial) with blood vitamin A (0.19 and 0.27)

Gingivitis with blood ascorbic acid $(0.18$ and 0.25$)$

Nasolabial seborrhea with blood vitamin A (0.16 and 0.19)

Folliculosis with dietary ascorbic acid (0.11 and 0.22)

Folliculosis with blood carotene (0.09 and 0.23) 
FIGURE 2. TEST OF CONTINGENCY

Percentoge of subjects with gingivitis
A. Positive Associotion

Incidence of gingivitis decreoses as the degree of deficiency (indicated by blood levels) decreoses.

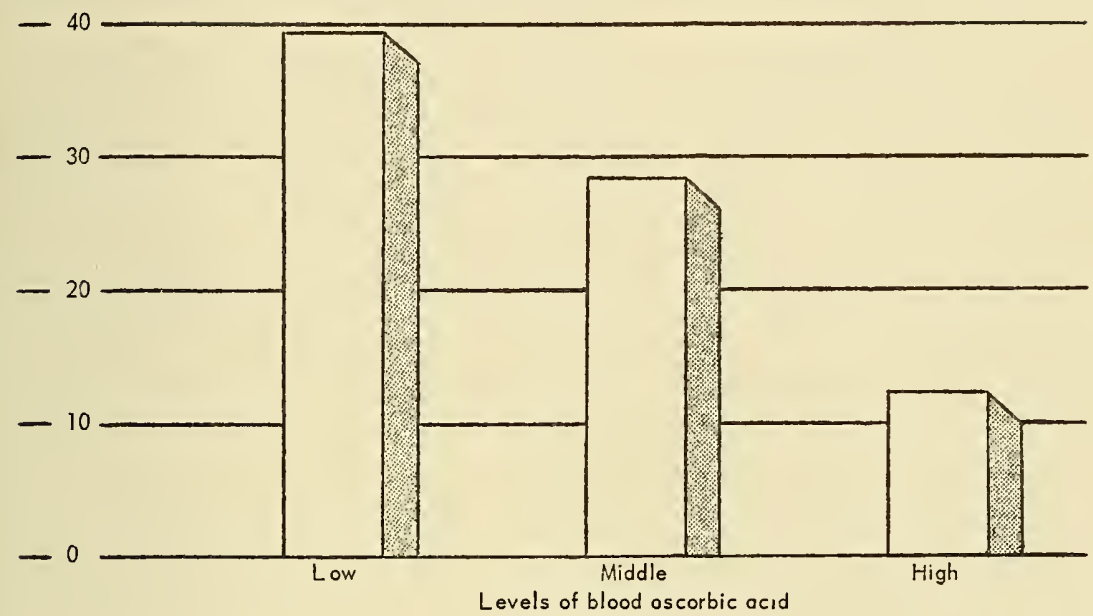

Percentage of subjects with popillae changes
B. Negative Association: Incidence of changes in tongue popillae increases as the degree of deficiency (indicated by blood levels) decreoses.

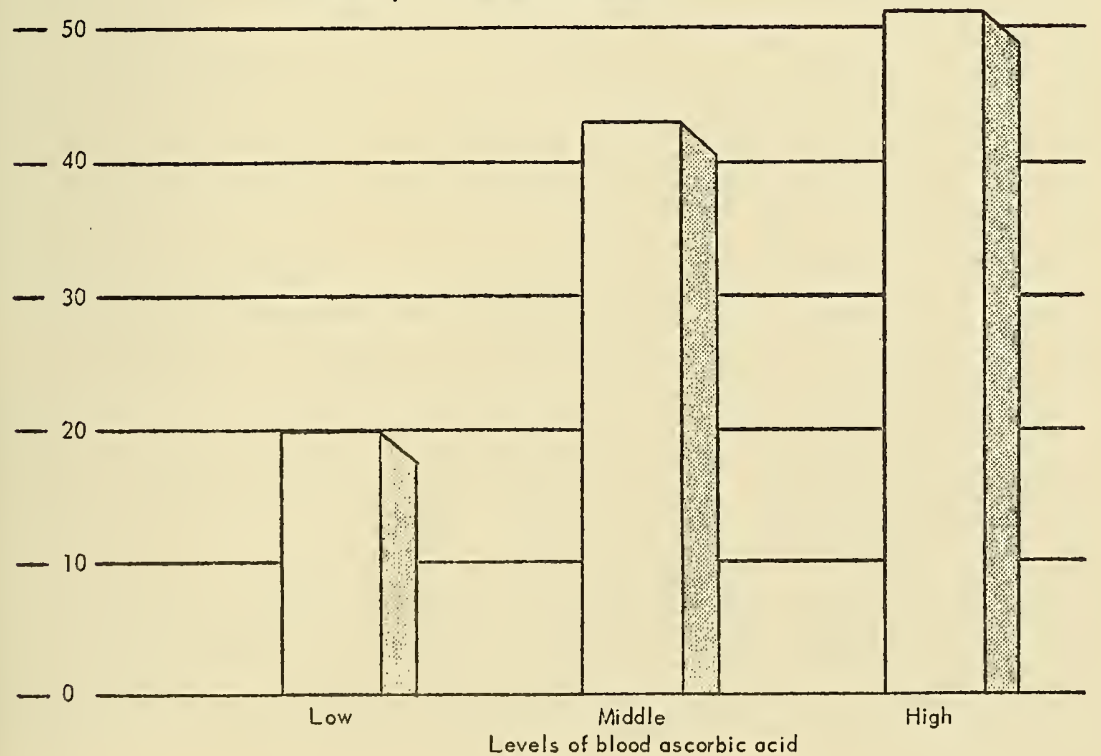


Acne (facial) with blood ascorbic acid (0.12 and 0.18)

Nasolabial seborrhea with blood ascorbic acid (0.11 and 0.18)

Fissuring of the tongue with blood carotene (0.08 and 0.13)

Lesions of the outer canthi with blood carotene $(0.06$ and 0.10$)$

Also a number of other positive associations were found to be significant for subjects at only one station (Table 5).

Of the 38 associations of physical signs with blood and dietary nutrients previously reported in the literature (Table 2) only 10 were found to be positively associated (significant at the 10 per cent level) by one or more stations. The failure of our data to provide statistically significant evidence for many of those associations may be due to one or more of the following factors: (1) For some associations there were not sufficient data to permit an analysis. That is, in the comparatively wellfed populations studied the incidence rates of certain physical signs were close to zero. (2) For some associations there may have been sufficient extraneous variations, such as in the recording of clinical data (Babcock, et al, 1952) to mask the true degree of association and to thwart the statistical efforts to estimate it. (3) The associations listed in the literature may not be true associations for the conditions of this study. That is, these associations may not actually exist for the populations studied or at the relatively high nutrient levels involved.

Of the 12 positive associations found to be significant for subjects at two or three stations, only three (gingivitis with blood and with dietary ascorbic acid and acne (facial) with blood vitamin A) were anticipated by our working list (Table 2) of associations previously reported in the literature. Each of the 9 additional associations noted might be explained in one of three ways. (1) It could be a true association, but not a cause-and-effect relationship, and therefore not included in Table 2 as of interest from the medical point of view.

(2) It could be a true cause-and-effect association that has not heretofore received sufficient attention to be included in Table 2. (3) The association may have been a chance one due to sampling, although the probability of such occurrences has been kept low, as indicated by the significance levels.

In addition to the unpredicted associations discussed in the preceding paragraph, six statistically significant, negative associations were noted; that is, associations in which the incidence rate of physical signs decreased as the degree of deficiency, indicated by the nutrient level, increased. Of these six negative associations, four were with hemoglobin and two were with blood ascorbic acid (Table 5). Only one negative association, increased vascularity of the bulbar conjunctiva with hemoglobin, was statistically significant for subjects at two stations. The possible explanations given in the preceding paragraph also might be applied here. 
Thus, since the significant negative associations with hemoglobin were noted only in children, one might postulate that both the hemoglobin level and the incidence of the physical sign were correlated with growth, and that the association between the physical sign and hemoglobin was spurious. The two negative associations with blood ascorbic acid were observed in the group of pregnant women.

\section{Comparison of Mean Nutrient Levels}

Whereas the hypothesis in the last section was concerned with relative distribution, an association was defined to exist here if a difference in mean levels of a blood constituent or dietary nutrient was found between subjects. with and without a physical sign. If such a difference was sufficiently large so as not likely to have occurred by chance $(P \leqq .10)$, as defined by the " $\mathrm{t}$ " test (Appendix C), it was listed as a significant association. In addition, as a matter of interest, the 20 per cent probability level is included in Table 6, where the results of this analysis are given in terms of the percentage differences between means. The percentage differences of the means were calculated by subtracting the mean value for subjects who showed the physical sign from the mean value for subjects who did not show the physical sign, and dividing this difference by arbitrary reference values* for blood constituents, and by the National Research Council recommended allowances for dietary nutrients. For those samples which included several age and sex groups, averages of the reference blood values and of the National Research Council dietary allowances, weighted according to the number of subjects in each age and sex group, were used.

For the subjects at four stations, blood ascorbic acid was found to be positively associated (10 per cent level, or less) with nasolabial seborrhea. That is, the mean levels of blood ascorbic acid for subjects who showed nasolabial seborrhea were 21-42 per cent lower than for subjects who did not show this sign.

The following associations between physical signs and blood levels were significant for subjects at three stations (differences between the means are given in parentheses):

Gingivitis with blood ascorbic acid ( $15-55$ per cent). Acne (facial) with blood vitamin A (12-44 per cent).

Increased vascularity of the bulbar conjunctiva with blood ascorbic acid (16-39 per cent).

Nasolabial seborrhea with blood vitamin A (17-24 per cent).

Gingivitis with blood carotene (8-22 per cent).

Folliculosis with blood carotene (8-10 per cent).

*Highest value in the "Fair" classification used by Bessey and Lowry (1947). 
Associations that were found to be significant for subjects at two stations, and the percentage differences between the means were as follows:

Fissuring of the tongue with blood carotene (7 per cent, 25 per cent).

Lesions of the outer canthi with blood carotene (15 per cent, 16 per cent).

Acne (facial) with blood ascorbic acid (12 per cent, 19 per cent).

Folliculosis with blood vitamin A (8 per cent, 18 per cent).

Stomatitis with blood hemoglobin (3 per cent, 3 per cent).

One negative (reverse) association was significant (10 per cent level, or less) for subjects at three stations. The mean dietary levels of riboflavin were 21-29 per cent higher for New Jersey, New York, and West Virginia subjects who had nasolabial seborrhea than for those who did not (Table 6). Negative associations were noted at two stations for stomatitis with dietary niacin ( -27 per cent, -41 per cent) and for increased vascularity of the bulbar conjunctiva with hemoglobin $(-2$ per cent, -6 per cent). A number of other associations were positively associated at some stations, but negatively associated at other stations, or were significantly associated at only one station (Table 6).

A significant difference in means indicates a group difference, but this difference does not necessarily apply to all individuals within the group. Figure 3 illustrates the extensive overlapping of the distributions of two groups that had a highly significant difference in their means.

The comparison of mean nutrient levels generally confirmed the analysis of the same data by the chi-square test of contingency. It should be pointed out, however, that these two tests are not equivalent. The comparison of means is concerned with the distance between two populations as indicated by their means, or centers of gravity, while the test of contingency is concerned with the proportion of subjects falling in several categories, or their distribution (Figures 2 and 3). Even though we should expect similar results in general from these two tests, they occasionally differ as a result of sampling fluctuations, especially when small numbers are involved. For example, the association of folliculosis with dietary ascorbic acid indicated by the test of contingency failed to materialize in the comparison of means. Two negative associations not revealed in the contingency test but brought out by the comparison of means were those of stomatitis with dietary niacin and nasolabial seborrhea with dietary riboflavin. We might note that although the definitions of positive and negative associations were as consistent as we could 
Difference between blood vitamin A means of New York subjects with and without nasolabial seborrhea as illustrated by the displacement of their frequency distributions.

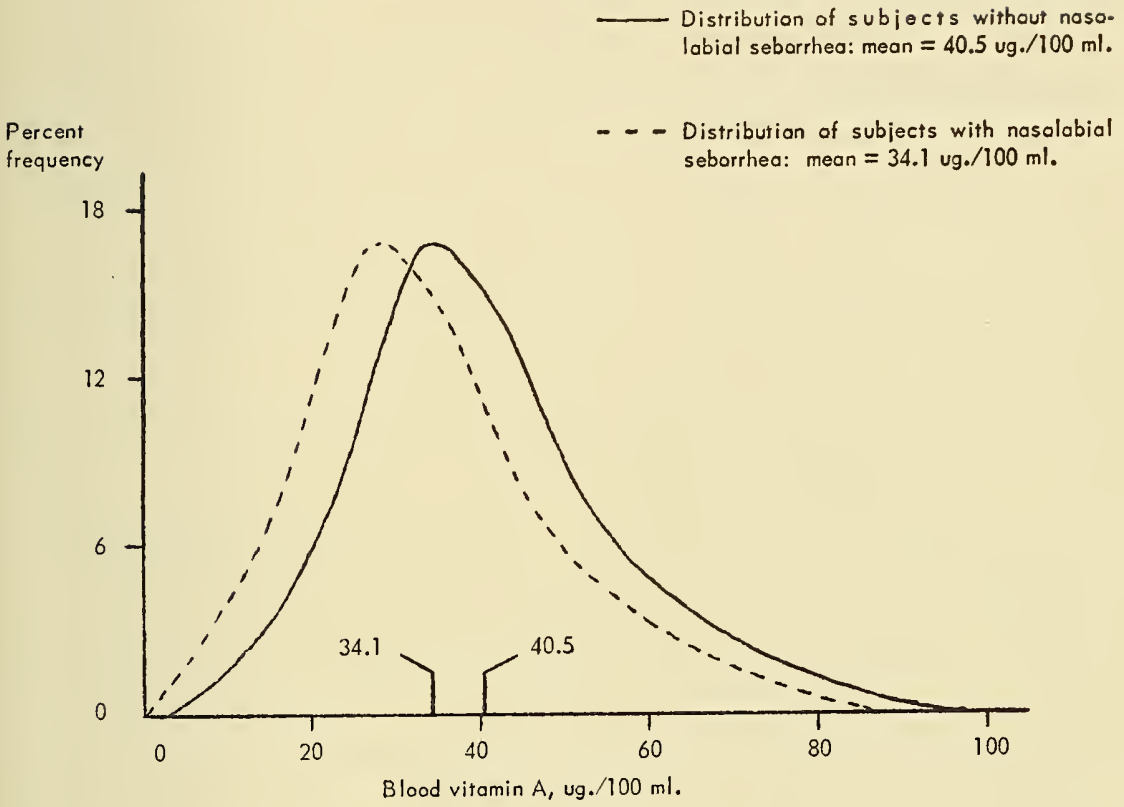

make them for the two methods, the one for the contingency test was more restricted, thus conceivably contributing to some of the inconsistencies.

\section{Discriminant Function}

In this analysis the association of physical signs with individual blood constituents and dietary nutrients was measured after removing the effects of other blood constituents and other dietary nutrients by statistical adjustment. Partial association coefficients, analogous to standard partial regression coefficients, were computed as indicators of the relative contribution of each nutrient towards discrimination. A test of significance was made for each nutrient under the hypothesis that its contribution to the association was zero. In Table 7, the partial association coefficients and their significance levels are given for each nutrient studied by this method. A partial association coefficient is listed in Table 7 as positive (positive association) if the incidence rate of the 
physical sign increased as the degree of deficiency, indicated by the blood (or dietary) level, increased. Over-all correlation indices and their significance levels also are given for the associations of multiple combinations of nutrients with the physical signs. Over-all correlation indices range from zero to 1.0 , but are always positive and therefore do not indicate the direction of the associations.

The partial association coefficients obtained by the discriminant function anaylsis are more critical measures of associations than either the chi-square test of contingency or the comparisons of mean nutrient levels described previously, because the partial association coefficients measure the degree of association after adjustments have been made for the effects of other nutrients. The data for the associations in West Virginia students, of goiter with blood ascrobic acid, dietary protein, and dietary ascorbic acid, illustrate this point. The chi-square test of contingency (Table 5) and the comparison of mean nutrient levels (Table 6) each showed highly significant associations of goiter with dietary ascorbic acid and with protein in West Virginia subjects. The partial association coefficients (Table 7) show, however, that although the association of goiter with dietary ascorbic acid was highly significant, the association with protein was no longer significant after adjustment had been made for the effects of ascorbic acid. The reason for this change is that a number of the subjects who had low dietary levels of ascorbic acid also had low protein levels (the dietary ascorbic acid-protein correlation coefficient was 0.352 , significant at the 1 per cent level). This tendency for the protein values to parallel the dietary ascorbic acid values, together with the association of dietary ascorbic acid and goiter, apparently caused significant associations to appear between protein and goiter in the chi-square test of contingency and in the comparison of mean nutrient levels. When an adjustment was made for the effects of blood and dietary ascorbic acid in the discriminant function analysis, this association between protein and goiter was reduced to a negligible quantity. These data strongly suggest that the association of protein with goiter was spurious, and merely a reflection of the ascorbic acidgoiter association.

Obviously, the adjustments made in a discriminant function analysis do not rule out factors that were not included in the analysis, and, like other statistical measures of associations, they do not establish cause-and-effect relationships. Thus, the highly significant association of goiter with dietary ascorbic acid noted in the preceding example does not indicate that an ascorbic acid deficiency causes goiter. Perhaps if data had been available for the iodine intakes of these students during puberty, inclusion of that factor in the analysis might have shown the association of dietary ascorbic acid with goiter to be spurious. 
The careful screening procedure for selecting factors to be considered in each discriminant function analysis, described in previous sections of this bulletin, was intended to insure consideration of all pertinent nutrient factors for which data were available. The discriminant function analysis was then used to eliminate spurious correlations among these nutrients, which may have been caused by the fact that if a person's diet is low in one nutrient, it is likely to be low in other nutrients also. Or, to put it differently, the fact that nutritional deficiencies usually occur in multiple form tends to cause spurious associations, which were at least partly eliminated by applying the discriminant function analysis.

The partial association coefficients listed under the blood and dietary nutrients in Table 7 indicate the relative contributions of the several nutrients individually toward predicting the presence or absence of a sign. Thus, for nasolabial seborrhea in Massachusetts subjects, it is seen that blood ascorbic acid and blood vitamin A contributed the same amount of relative information, while dietary riboflavin contributed nothing when in combination with the other two nutrients.

For the prediction of gingivitis in Maine and Rhode Island subjects, blood ascorbic acid was found to be more effective than dietary ascorbic acid. Likewise, in nearly all of the other associations that provided a comparison at any station of the contribution of blood ascorbic acid with that of dietary ascorbic acid, the coefficients for dietary ascorbic acid were either less than those for blood ascorbic acid, or were negatively correlated with the physical signs. As with ascorbic acid, the blood levels of vitamin A (and its provitamin, carotene), were usually more effective than dietary intakes in predicting whether or not subjects had certain physical signs, as, for example, folliculosis.

For the subjects at four stations an association signficant at the 20 per cent level, or less, was observed between acne (facial) and blood vitamin A. The following associations were significant at three stations:

Increased vascularity of the bulbar conjunctiva with blood ascorbic acid.

Nasolabial seborrhea with blood ascorbic acid and also with blood vitamin A.

Gingivitis with blood ascorbic acid.

For the subjects at two stations blood carotene was significantly associated with gingivitis, folliculosis, and xerosis, but a highly significant negative association with xerosis was also noted at another station. The directions of the association of xerosis with blood vitamin $\mathrm{A}$ at different stations were not consistent-two positive and two negative. 
Other negative associations significant for subjects at two stations were as follows:

Nasolabial seborrhea with dietary riboflavin.

Stomatitis of the buccal mucosa with dietary niacin.

Perifollicular petechiae with dietary ascorbic acid.

It will be noted that of the above-mentioned associations, significant for subjects at two or more stations, the positively directed associations were with blood constituents, and the negatively directed (reverse) associations were with dietary nutrients. The three negative associations of physical signs with dietary nutrients were contrary to observations previously reported in the literature (Table 2). This inconsistency suggests the possibility that the samples studied may have contained a number of subjects in whom the physical sign had been caused by some factor other than malnutrition, and who were attempting to cure the condition by high dietary intakes. It also is pertinent that the literature cited is concerned with associations in the deficiency state, whereas the data given here are based on intakes ranging from deficient to excess, with a predominance of the latter. As an example, let us see why the New Jersey data indicated a highly significant (1 per cent level) reverse association of niacin with stomatitis of the buccal mucosa, contrary to literature reports that a deficiency of niacin may cause such stomatitis.

The dietary data showed that the twenty-two subjects who had stomatitis had an average niacin intake of $25 \mathrm{mg}$. per day. Only four of these subjects consumed less than the National Research Council recommended allowance for niacin and these four each consumed more than $12 \mathrm{mg}$., which probably met their minimum requirements. It thus appeared that the association under examination was not concerned with the effects of niacin deficiency. The data might be explained by postulating either that an excess of niacin caused stomatitis, or that a one-in-a-hundred chance association had occurred. It was noted that three subjects who had stomatitis (presumably of non-nutritional origin) happened to have extremely high niacin intakes. These subjects were large (150 to 200 lbs.), active men who stated, under careful cross-examination at the dietary interview, that they ate quantities of food which were later calculated to contain over 6,000 Calories per day. Since there were only twenty-two subjects with stomatitis, the data from these three subjects carried great weight in the analysis. Rejection of these three subjects would change this partial association coefficient from -.14 ( 1 per cent level) to .01 (not significant), with little change in the other coefficients.

The preceding example of apparently a chance association occurring at the 1 per cent level emphasizes that coefficients significant at 
the 10 per cent and 20 per cent levels must be interpreted with caution. Theoretically, 5-10 per cent of the coefficients listed in the tables as being significant at the 10 per cent level, and 10-20 per cent of those listed as being significant at the 20 per cent level, were caused by chance sampling rather than by true associations. To minimize the effects of sampling errors on interpretation of the data, an association of a physical sign with a blood constituent or a dietary nutrient has been listed in the summary of this paper as "significant" only if the discriminant function analysis showed it to be significant at the 5 per cent level, or less, for subjects at one station, at the 20 per cent level, or less, for subjects at another station, and gave no negative coefficients significant at the 20 per cent level at any station.

The over-all correlation indices, also given in Table 7 , provide a measure of the precision with which individual physical signs could be predicted from various combinations of blood and dietary data. An over-all correlation index greater than about 0.7 would indicate that a combination of nutrients had effectively distinguished between groups of subjects with and without a physical sign. Although many of the over-all correlation indices given in Table 7 were statistically significant, the low values of these coefficients (only one exceeded 0.33) show that, under the conditions of these studies, it was not possible to effectively predict the presence of physical signs from combinations of blood and dietary data. Because of the careful screening procedure used to select the nutrients for this phase of the study, it seems unlikely that the inclusion of other nutrients in the combined associations would increase the ability to discriminate between subjects with and without physical signs.

\section{Effect of Nutritional Status on Associations}

The procedures used to test the theory that higher correlations between dietary, blood, and medical data may be obtained from subjects of low nutritional status necessarily limited this phase of the study to those nutrients for which blood data, as well as dietary and medical data, were available. The analysis was thus restricted to ascorbic acid (dietary, blood, and associated physical signs), and vitamin A (dietary and blood vitamin A, blood carotene, and associated signs). A more severe limitation required by the procedure was that there be sufficient numbers of subjects having physical signs, low blood levels, and low dietary levels to provide valid tests.

Table 8 gives the blood-dietary correlation coefficients for ascorbic acid and vitamin A for each degree of severity of associated physical signs. Physical signs for which less than five individual correlation 
coefficients could be calculated were not included in that table. The correlation of blood ascorbic acid with dietary ascorbic acid for New Jersey men having different degrees of thickening of the bulbar conjunctiva illustrates the theory. As the severity of the physical sign increased from "normal," through "mild" and "moderate," to "severe," the magnitude of the correlation coefficients increased from 0.09 , through 0.25 and 0.36 , to 0.95 . The numbers of subjects having various degrees of the sign were, however, so small that this trend was not statistically significant. Data from Maine children for the same association showed a slight trend in the opposite direction.

Of the twenty-three sets of comparative values given in Table 8 , about half showed a tendency for the correlation coefficient to increase with severity of associated sign, one-fourth showed a reverse trend, and one-fourth showed no trend. Since many of the individual correlation coefficients were not significant $(P>0.20)$, some of the trends (both positive and reverse) may easily have been due to chance. Of the significant correlation coefficients given in Table 8, eight of the ten pairs of coefficients increased with increasing severity of the physical sign. Collectively, these data provide some support for the theory, but indicate that exceptions may occur frequently.

Putnam, et al (1949) obtained lower correlations of blood ascorbic acid with dietary ascorbic acid from subjects with high levels of intake than from subjects with low intakes. They suggested that with the serum level at or near the renal threshold much of the ingested vitamin may have been excreted. They also noted a closer fit of the data to the regression lines at intakes less than 60 milligrams daily than at higher levels.

The data in Table 8 were used to estimate the effect of nutritional status, as defined by physical signs, on the associations of blood constituents with dietary nutrients. Attempts also were made to estimate the effect of nutritional status, as defined by blood levels, on the associations of physical signs with dietary nutrients, and the effect of nutritional status, defined in terms of dietary levels, on the associations of physical signs with blood constituents. The latter studies were made by comparing $\mathrm{C}$-values obtained from chi-square tests on subjects of low nutritional status with the corresponding $\mathbf{C}$-values given in Table 5 for all subjects. This test was not a sensitive one, but it showed effects of nutritional status in agreement with the theory for the association of vascularity of the bulbar conjunctiva with ascorbic acid in Rhode Island subjects. Thus the C-value for the association of this sign with dietary ascorbic acid was increased from 0.151, significant at the 5 per cent level (Table 5), to 0.300 , significant at the 1 per cent level when the sample was restricted to subjects whose blood 
levels were "fair" or "poor" by the classification of Bessey and Lowry (1947). Likewise, the C-value for the association of this sign with blood ascorbic acid was increased from 0.113 , significant at the 5 per cent level, for all subjects to 0.238 , significant at the 10 per cent level, for subjects whose diet supplied less than 70 per cent of the National Research Council recommencled allowance for ascorbic acid. Similar effects of nutritional status were noted, with some exceptions, for the associations of gingivitis with dietary and blood ascorbic acid in Maine, New Jersey, and Rhode Island subjects.

The data cited in the preceding paragraphs suggest that subjects of low nutritional status may frequently show higher associations among dietary, blood, and medical data than subjects having high nutritional status, but such trends individually have not been shown to be statistically significant.

\section{INTERPRETATION OF RESULTS}

This study was designed to provide information on the complex relationships between dietary intake, biochemical processes, and physical signs as they exist in normal population groups throughout the Northeast Region. This plan necessarily precluded the control of many extraneous sources of variation in the data and thus lowered the probability of establishing clear-cut relationships, but at the same time it gave a more comprehensive picture than is possible under the artificial conditions of controlled experimentation.

The studies reported here of relationships between blood constituents and their corresponding dietary nutrients showed, as might be expected, that the distribution of blood ascorbic acid reflected that of dietary ascorbic acid, that blood hemoglobin was related to dietary protein and iron, and that blood carotene paralleled blood vitamin A. Relationships of dietary vitamin A (including carotene) with the corresponding blood nutrients were scarcely detectable because of the wide daily fluctuations in dietary levels and the effects of tissue reserves on blood levels of this vitamin. A further study of blood and dietary relationships revealed a number of other statistically significant correlations, but these were thought to be mostly spurious correlations caused by the tendency of natural diets rich in a given nutrient to contain high levels of some other nutrients.

The investigation of relationships between quantitative measurements of blood constituents (and also of dietary nutrients) on the one hand, and qualitative ratings of clinical signs, on the other, was accomplished by means of the chi-square test of contingency, supplemented by a comparison of the mean blood (or dietary) levels of subjects who had 
clinical signs with those who did not have clinical signs. These studies showed that a number of physical signs were significantly associated with blood levels in two or more population groups, but gave little evidence of relationships of physical signs with dietary nutrients.

Because of the appreciable number of spurious correlations observed between various blood and dietary nutrients, the analyses were extended by means of a relatively new statistical method, the discriminant function, to adjust for any effects of certain nutrients on the associations of other nutrients with physical signs. The associations selected for this phase of the study were those that had previously been shown to be associated by the comparisons of means. A number of the associations that had previously been found to be significant were no longer significant after adjustment had been made for the effects of other nutrients. The discriminant function analyses showed seven associations (listed in the Summary) of physical signs with blood constituents that were significant for two or more population groups. Blood constituents were usually more effective than dietary nutrients as a means of predicting which subjects had physical signs and which did not. In no case could the presence of a physical sign be accurately predicted from any of the combinations of blood and dietary nutrients that were tested.

The data cited here illustrate the need for caution in interpreting survey results. The possibility that spurious or chance associations may account for some of the significant associations (both positive and negative) has been discussed. It also has been emphasized that associations that are significant for a group of subjects are not necessarily applicable to all individual subjects, and, of course, cannot always be taken as an indication of cause and effect no matter how refined the statistical analysis. Neither can the failure to obtain statistical proof of an association be taken as evidence that a relationship does not exist. The uncontrolled variation present in each measurement and the low frequency of nutritional deficiencies in well-fed population groups may combine to obscure such relationships. Sources of uncontrolled variation have been discussed in detail elsewhere (National Research Council, 1949; Babcock, et al, 1952; Young, et al, 1952; Clayton, et al, 1953).

Another complication that must be considered in studying relationships among various measures of nutritional status is that these relationships may not be the same in the well-nourished organism as in the deficient one. Examination of the data reported here suggests that subjects of low nutritional status may show higher associations 
among dietary, blood, and medical data than subjects having high nutritional status.

The implications of these findings are that cross-section type statistical studies of the nutritional status of normal population groups may reveal relationships between dietary intake, blood chemistry, and physical signs, but that these relationships must be studied further in longitudinal studies under controlled conditions to establish their validity.

\title{
SUMMARY
}

Data from over 1,500 subjects, representing various population groups in the Northeast Region of the United States, have been analyzed for evidence of relationships between dietary intake, blood chemistry, and physical signs. Significant correlations were observed in most population groups for the following blood constituents and dietary nutrients:

\author{
Hemoglobin with dietary protein \\ Hemoglobin with dietary iron \\ Blood vitamin A with blood carotene \\ Blood ascorbic acid with dietary ascorbic acid
}

In analyzing the data for relationships between blood constituents and physical signs and between dietary nutrients and physical signs, the data were screened to locate nutrients that may have been sources of spurious associations, and adjustments were made statistically to compensate for any effects of those nutrients on the associations of other nutrients with physical signs. The following associations were found to be significant in studies of two or more population groups:

Acne (facial) with blood vitamin A

Increased vascularity of the bulbar conjunctiva with blood ascorbic acid

Nasolabial seborrhea with blood ascorbic acid

Nasolabial seborrhea with blood vitamin A

Gingivitis with blood ascorbic acid

Gingivitis with blood carotene

Folliculosis with blood carotene

Throughout this study particular consideration has been given to factors that may affect the interpretation of the data. The findings suggest that cross-section type studies of normal population groups should be supplemented by longitudinal studies under controlled conditions. 


\section{STATISTICAL APPENDIX}

\section{Appendix A. Chi-square of Contingency}

The chi-square tests of contingency were applied according to the formula that can be found in Goulden (1939). Special attention was paid where needed to expected values and to the correction for continuity. In some of the 2 by 2 tables where a directional result was anticipated, a one-tailed chi test was used as a more powerful statistic in testing for contingency. In the 2 by 3 tables where it was apparent that a linear relation between the two variates existed, the value of chisquare was partitioned into linear component and remainder, the test being made with one degree of freedom. Such a partition was suggested by Brandt (1952). Again, the chi test with the one degree of freedom associated with the linear partition was used to test a one-side hypothesis only where a directional result was anticipated.

\section{Appendix B. Coefficient of Mean Square Contingency}

This coefficient, due originally to Karl Pearson (1904), was calculated according to the formula, $\mathrm{C}=\sqrt{\times^{2} /\left(\times^{2}+N\right)}$, which can be found in Goulden (1939). Since $\mathrm{C}$ is independent of the number of individual contributions to chi-square as well as depending on both chisquare and $\mathrm{N}$, it is not strictly comparable from test to test where neither the degrees of freedom nor $\mathrm{N}$ were constant. Moreover, for those accustomed to measures of association with a range of -1 to +1 , this coefficient may offer further difficulty. It was calculated for data of the nature used in this research that the values for $\mathrm{C}$ would range from a minimum of zero to a maximum of about 0.6. The values are always positive and do not indicate the direction of an association. Despite these obvious limitations, it was felt that the advantage of having at least an approximate idea of the magnitude of the association (other than indicated by the level at which the values of $\times^{2}$ would be significant) would justify the computation of this statistic.

Where chi-square was partitioned into one degree of freedom for linearity, the corresponding $\mathrm{C}$ value was not computed lest it lose what little basis it had for comparison.

Other indexes of contingency were available, as can be found in Kendall (1945). These proved to have even more serious limitations than the one presented here.

\section{Appendix C. The " $t$ " Test}

Of the many references explaining the use of the "t" test, Dixon and Massey (1951) offer an especially lucid account of the type of 
hypotheses, critical regions, and procedure to follow in accepting or rejecting hypotheses. The effect of the failure of some of the necessary assumptions to hold has been summarized by Cochran (1947). In the applications here, the procedure has been scrutinized carefully in light of the necessary assumptions and limitations to substantiate the validity of the test as used as well as the conclusions derived from it.

\section{Appendix D. The Discriminant Function}

Originally proposed by Fisher (1936) as a method employing concomitant measurements of several characteristics as a basis for indentifying an object with one or the other of two population types, the discriminant function has since been applied to many and diverse types of problems. A recent comprehensive survey of discriminatory analysis has been made by Hodges (1950). Cochran (1948) treated it as a generalized linear regression in which the covariance matrix of the predictors included the variances between means as well as the within variances. It has been shown by many writers, Kendall (1946) for one, that the tests of significance for each predictor as well as for the discriminant itself are available from the usual multiple regression theory under the assumption that $y$, the population designator, is fixed and the x's or predictors have a multivariate normal distribution. Although this assumption admittedly was not met in the data presented here, there has been considerable evidence (Cochran, 1947) that any resultant shift in the probability levels would very likely be small. More than offsetting this minor disadvantage is the wealth of information available from multivariate analysis not otherwise obtainable in considering a pair of variables separately.

In the application of discriminant function theory here, emphasis has been placed on the information derived from the predictors themselves individually and collectively as indicators of their relationship to the two populations used rather than the original taxonomic use. Since there seemed to be no widely accepted terminology in the literature describing the variables of this function (possibly due to the many fields of application), the term "partial association coefficient" was used here to refer to this specific role of the predictors. It should be noted that this term has been employed by other writers in different kinds of analysis but in the same sense. 


\section{REFERENCES}

American Medical Association Council on Foods and Nutrition. Vitamin deficiencies; stigmas, symptoms and therapy. J. Am. Med. Assn., 131: 666 (1946).

Babcock, M. J., A. Hughes Bryan, M.D., Mary M. Clayton, Walter D. Foster, J. J. Lawless, M.D., Ruth Tucker, Anne W. Wertz, and Charlotte M. Young. Cooperative nutritional status studies in the Northeast Region.

II. Physical Findings. N. J. Agr. Exp. Sta. Bull. No. 763 (1952).

Bessey, O. A., and O. H. Lowry. Nutritional assay of 1200 New York State school children. Meals for Millions, New York State Joint Legislative Committee on Nutrition, pp. 167-192 (1947).

Brandt, A. E., Personal communication, 1952.

Carroll, Marian E., M. A. Wharton, B. L. Anderson, and E. C. Brown. Group method of food inventory vs. individual study method of weighed food intake. J. Am. Diet. Assn., 28: 1146 (1952).

Clayton, Mary M., M. J. Babcock, Walter D. Foster, Sam Stregevsky, Ruth E. Tucker, Anne W. Wertz, and H. H. Williams. Cooperative nutritional status studies in The Northeast Region. V. Blood Findings. Maine Agr. Exp. Sta. Bull. No. 516 (1953).

Cochran, W. G., Some consequences when the assumptions for the analysis of variance are not satisfied. Biometrics, 3: 22 (1947).

Cochran, W. G. Unpublished lecture notes on advanced experimental statistics. Institute of Statistics, Raleigh, N. C. (1948) .

Darby, William J. The influence of some recent studies on the interpretation of the findings of nutrition surveys. J. Am. Diet. Assn., 23: 204 (1947).

Dixon, W. J., and F. J. Massey. Introduction to statistical analysis. McGraw-Hill Book Company, New York, pp. 97-107 (1951).

Fisher, R. A. The use of multiple measurements in taxonomic problems. Ann. Eug. London, 8: 376 (1936).

Goulden, C. H. Methods of statistical analysis. John Wiley \& Sons, New York, pp. 95-113 (1939).

Hodges, Joseph L. Survey of discriminatory analysis. Project Report, U.S.A.F. School of Aviation Medicine, Randolph Field, Texas. (1950).

Jolliffe, N., F. F. Tisdall and P. R. Cannon. Clinical nutrition. Paul B. Hoeber, New York, N.Y., pp. 49-116 (1950).

Kendall, M. G. The advanced theory of statistics. Vol. I. Charles Griffin \& Company, London, pp. 308-23 (1945).

Kendall, M. G. The advanced theory of statistics. Vol. II. Charles Griffin \& Company, London, pp. 341-8 (1946) .

Kimble, M. S., and E. S. Gordon. The importance of riboflavin and ascorbic acid in the utilization of vitamin A. J. Biol. Chem., 128: lii (1939).

Mayer, J., and W. A. Krehl. The relation of diet composition and vitamin $\mathrm{C}$ to vitamin A deficiency. J. Nutr., 35: 523 (1948).

Mayer, J. Rev. canad. de biol. 8: 488 (1949) [ (Nutr. Reviews) 10: 217 (1952)].

Merrow, Susan B., R. F. Krause, J. H. Browe, C. A. Newhall and H. B. Pierce. Relationships between intake and serum levels of ascorbic acid, vitamin $A$, and carotene of selected groups of children with physical signs of vitamin deficiencies. Jour. Nutr., 46: 445 (1952).

National Research Council Reprint and Circular Series. No. 129. Recommended dietary allowances (1948).

National Research Council Bulletin. No. 117. Nutrition surveys: Their techniques and value (1949).

Northeast Region. Cooperative nutritional status studies in the Northeast Region. I. Techniques. Cornell Univ. Agr. Exp. Sta. Memoir 307 (1951) .

Pearson, Karl. On the theory of contingency and its relation to association and normal correlation. Drapers' Company Research Memoirs, Biometric Series I. Dulau and Company, London. (1904).

Pett, L. S. Errors in applying nutrient allowances to dietary surveys or food policies. Can. J. Pub. Health 36: 69 (1945).

Putnam, P., D. F. Milam, R. K. Anderson, W. J. Darby, and P. A. Mead. The statistical association between the diet record of ascorbic acid intake and the blood content of the vitamin in surveyed populations. Milbank Mem. Fund Quart. 27: 355 (1949). 
Sinclair, H. M. The assessment of human nutriture. Vitamins and lformones 6: 101 162. Academic Press, New York (1948).

Tucker, Ruth E., Faith W. Chalmers, Helen N. Church, Mary M. Clayton, Walter D. Foster, Lorraine O. Gates, Gladys C. Hagan, Betty F. Steele, Anne W. Wertz, and Charlotte M. Young. Cooperative nutritional status studies in the Northeast Region. IV. Dietary findings. Rhode Island Agr. Expt. Sta. Bull. No. 319 (1952).

Young, Charlotte M., Faith W. Chalmers, Helen N. Church, Mary M. Clayton, Lorraine O. Gates, Gladys C. Hagan, Betty F. Steele, Ruth E. Tucker, Anne W. Wertz, and Walter D. Foster. Cooperative nutritional status studies in the Northeast Region. III. Dietary methodology studies. Mass. Agr. Expt. Sat. Bull. No. 469 (1952). 
Table 1. Classification of Subjects by Blood Levels

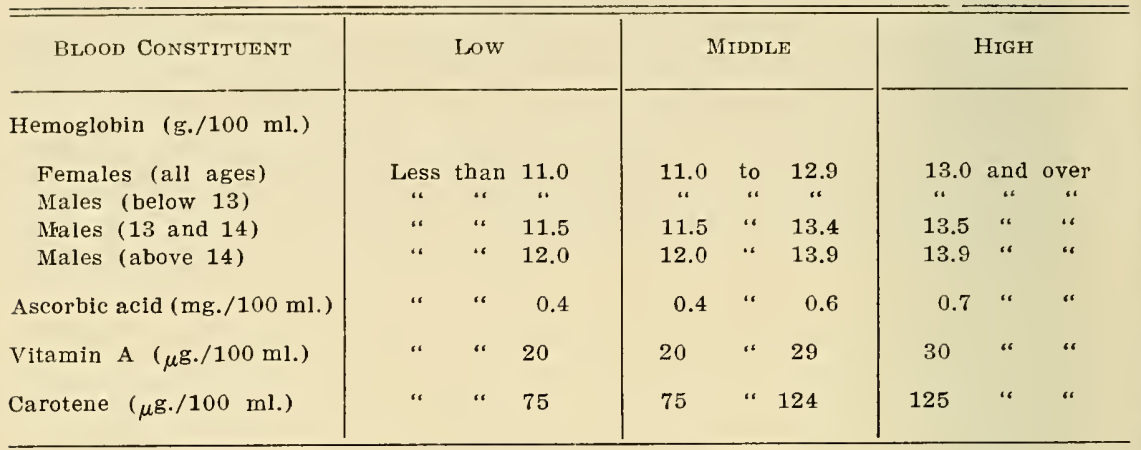

\section{Table 2. List of Associations Between Physical Signs and Nutrients*}

Vitamin $A-$

'Thitmin'-

Riboflavin-

Niacin-

Ascorbic Acid-

Protein-

Iron-
Eyes: Blepharitis

Eyes: Thickening of the bulbar conjunctiva

Skin: Acne (facial)

Skin : Xerosis

Skin : Folliculosis

Neurological Findings

Eyes: Blepharitis

Eyes: Thickening of the bulbar conjunctiva

Eyes: Lesions of the outer canthi

Skin: Nasolabial seborrhea

Skin : Acne (facial)

Lips: Cheilosis (including angular stomatitis)

Tongue: Magenta

Tongue: Changes in papillae

Tongue: Swelling

Lips: Cheilosis (including angular stomatitis) Buccal Mucosa: Stomatitis

Tongue :Reddened

Tongue: Changes in papillae

Tongue : Swelling

Gums : Gingivitis

Skin : Perifollicular petechiae

Skin : Purpura

Tongue: Reddened

Lips: Cheilosis (including angular stomatitis)

*Adapted from similar lists published by the American Medical Association (1946) and by Jolliffe, Tisdale and Cannon (1950). 
Table 3. Simple Correlation Coefficients. Coefficients and Their Significance Levels for the Correlations of Blood Constituents with Related Dietary Nutrients

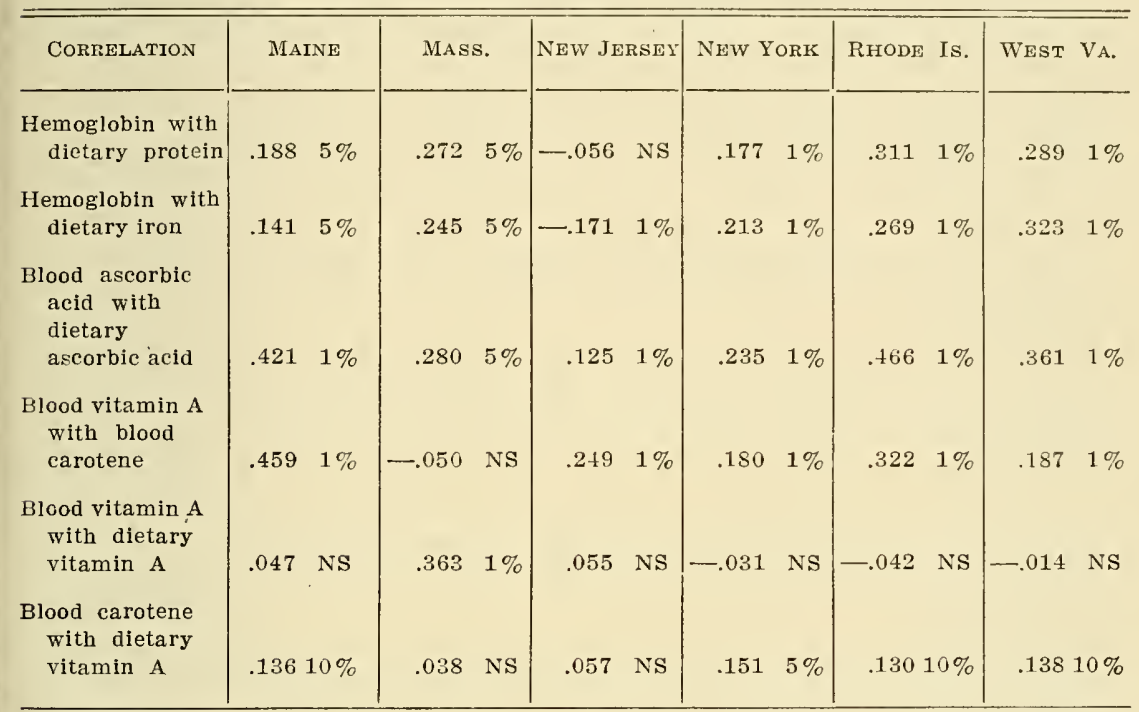


Table 4. Simple Correlation Coefficifints (continued). Coeffitijate and Their Significance levels for the Correlations of Blood and Dietary Nutrients Other Than Those Listed in Table 3

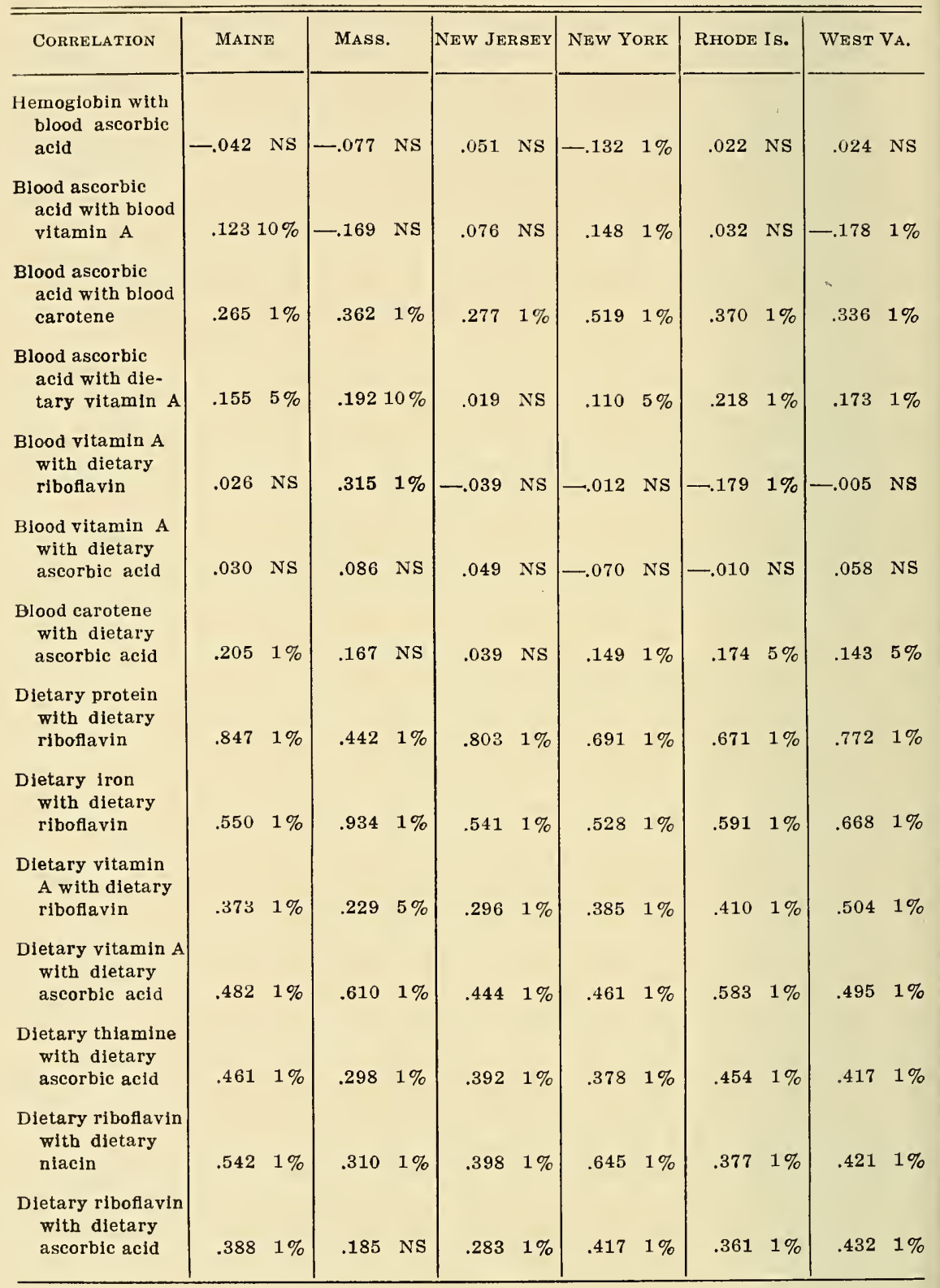




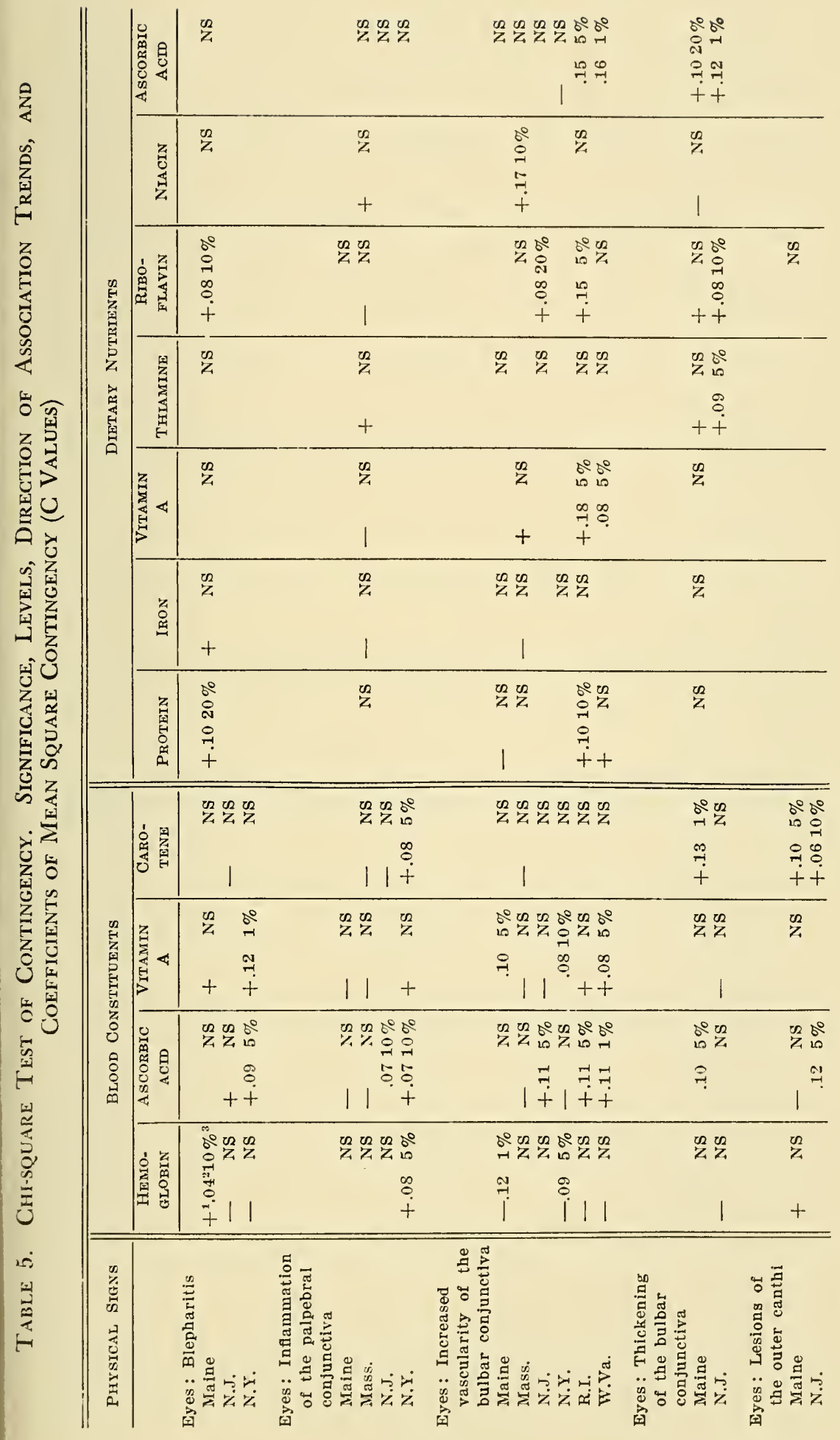




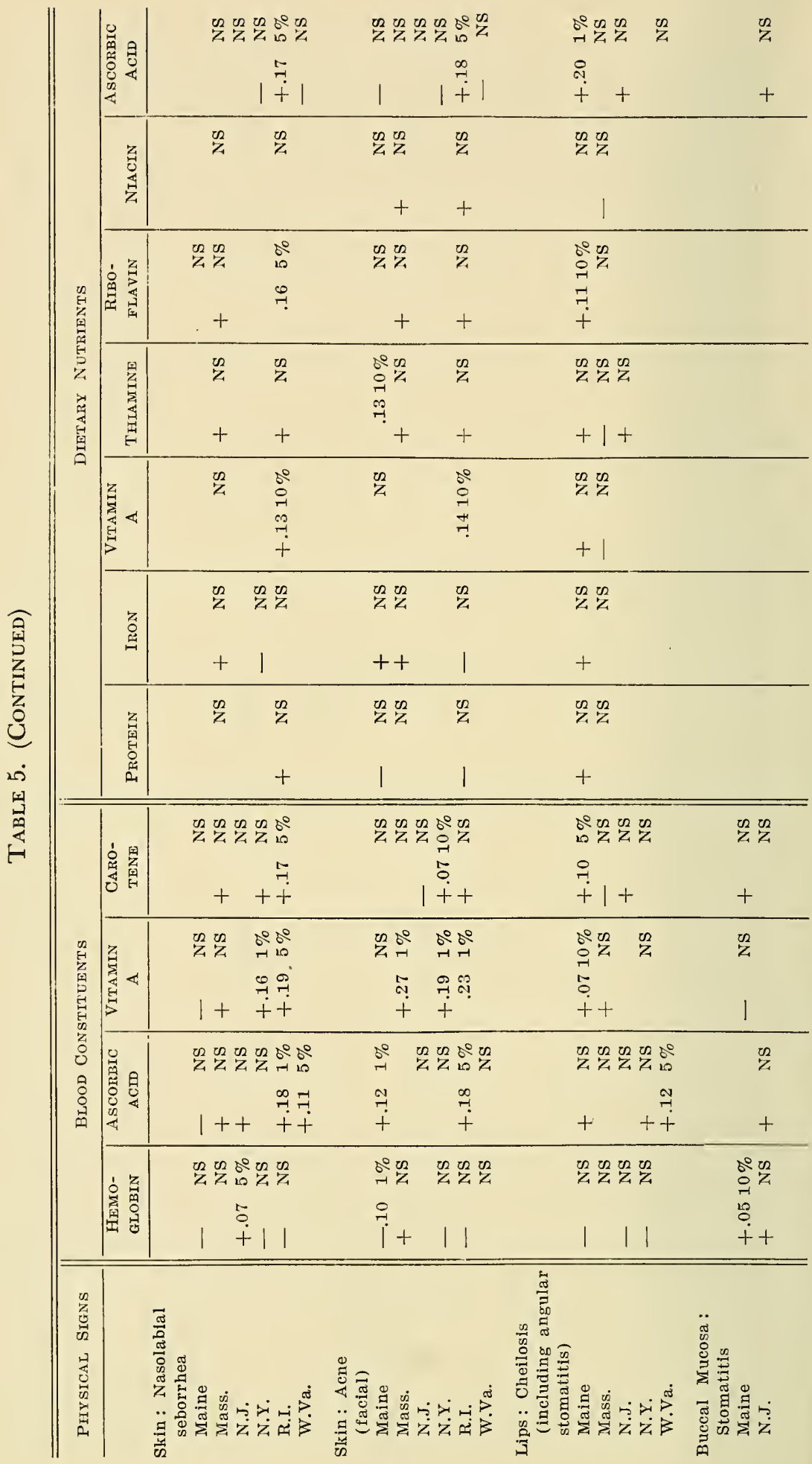




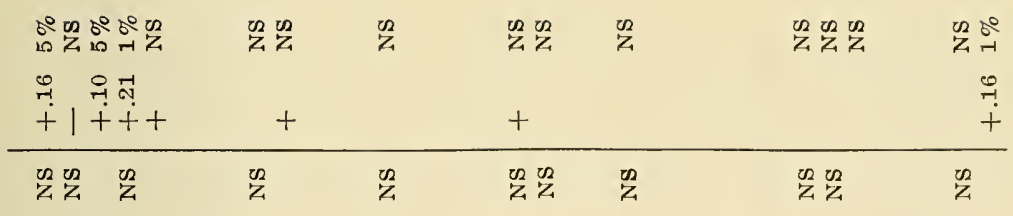

\begin{tabular}{|c|c|c|c|c|c|c|}
\hline+11 & + & + & 1 & 1 & + & + \\
\hline 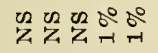 & $\frac{\pi}{7}$ & $\frac{\pi}{Z}$ & $\tilde{z}_{z}^{2}$ & $\tilde{z}^{2}$ & 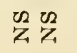 & $\frac{\pi}{2}$ \\
\hline
\end{tabular}

\begin{tabular}{|c|c|c|c|c|c|c|}
\hline$+\stackrel{\text { สุ }}{+}$ & I & & + & & 1 & + \\
\hline 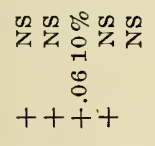 & + & $\frac{\pi}{z}$ & $\begin{array}{l}\frac{\sigma 2}{Z} \\
+ \\
\end{array}$ & $\begin{array}{l}\circ \\
\circ \\
\circ \\
\infty \\
\stackrel{+}{+}\end{array}$ & $\begin{array}{l}\frac{\pi}{2} \\
1\end{array}$ & \\
\hline 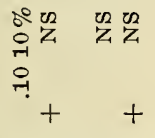 & ${ }^{2}$ & $\begin{array}{l}\delta^{\circ} \\
\text { \& } \\
\text { oे } \\
\text { Tे }\end{array}$ & $\begin{array}{l}\frac{\pi}{2} \frac{\pi}{2} \\
+\end{array}$ & 曾 & 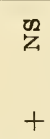 & $\begin{array}{l}v_{2}^{2} \\
+\end{array}$ \\
\hline 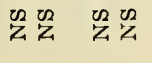 & $\stackrel{\pi}{Z}$ & $\tilde{z}_{z}^{2}$ & $\frac{\pi}{z}$ & 80 & $\stackrel{0}{2}$ & $\check{n}_{z}^{n}$ \\
\hline
\end{tabular}

\begin{tabular}{|c|c|c|c|c|c|c|c|}
\hline 11 & 1 & 1 & 1 & + & $\stackrel{t}{+}$ & 1 & \\
\hline$\frac{\sigma_{2}^{2}}{2}$ & 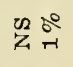 & $\frac{\pi}{2}$ & $\frac{\pi}{2}$ & 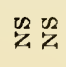 & $\begin{array}{l}\circ \\
\stackrel{7}{0}\end{array}$ & 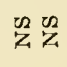 & $\begin{array}{l}50 \\
-1\end{array}$ \\
\hline+ & $\stackrel{\text { ๙ิ }}{\stackrel{+}{+}}$ & & & +1 & $\stackrel{\infty}{\circ}$ & 1 & $\stackrel{\pi}{\stackrel{7}{+}}$ \\
\hline
\end{tabular}

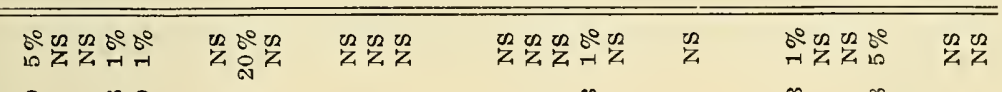

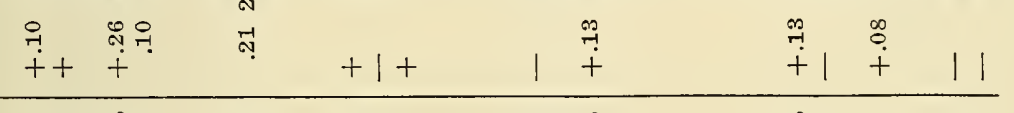

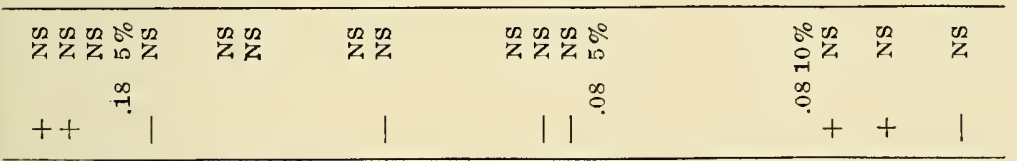

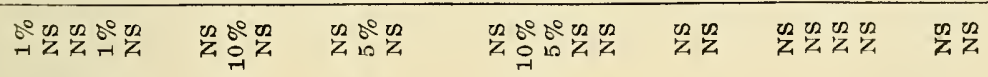

\begin{tabular}{|c|c|c|c|c|c|}
\hline 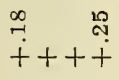 & $\stackrel{\text { i̊ }}{i}$ & $\stackrel{\infty}{\ddot{m}}+$ & $\stackrel{0}{10}$ & $1+$ & | 1 \\
\hline 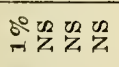 & $\begin{array}{l}n \\
z \\
z\end{array}$ & $\sum_{z}^{50}$ & 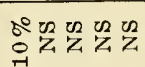 & 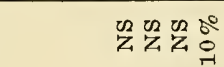 & $\frac{\pi n}{z} z$ \\
\hline$\stackrel{8}{i}++1$ & "艹 & $\left.\right|^{\mathscr{q}}$ & $\stackrel{\circ}{i}+11$ & $1+8$ & \\
\hline
\end{tabular}

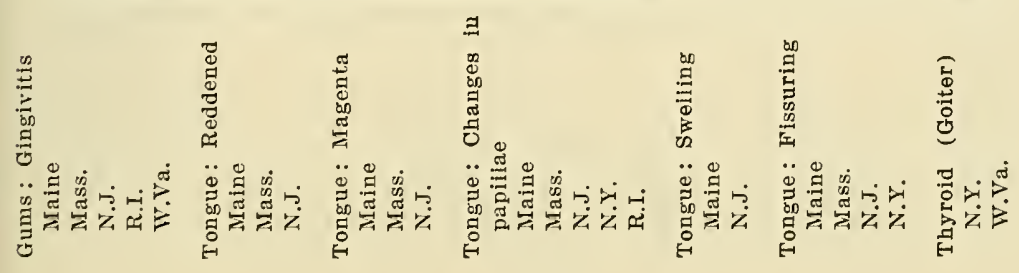




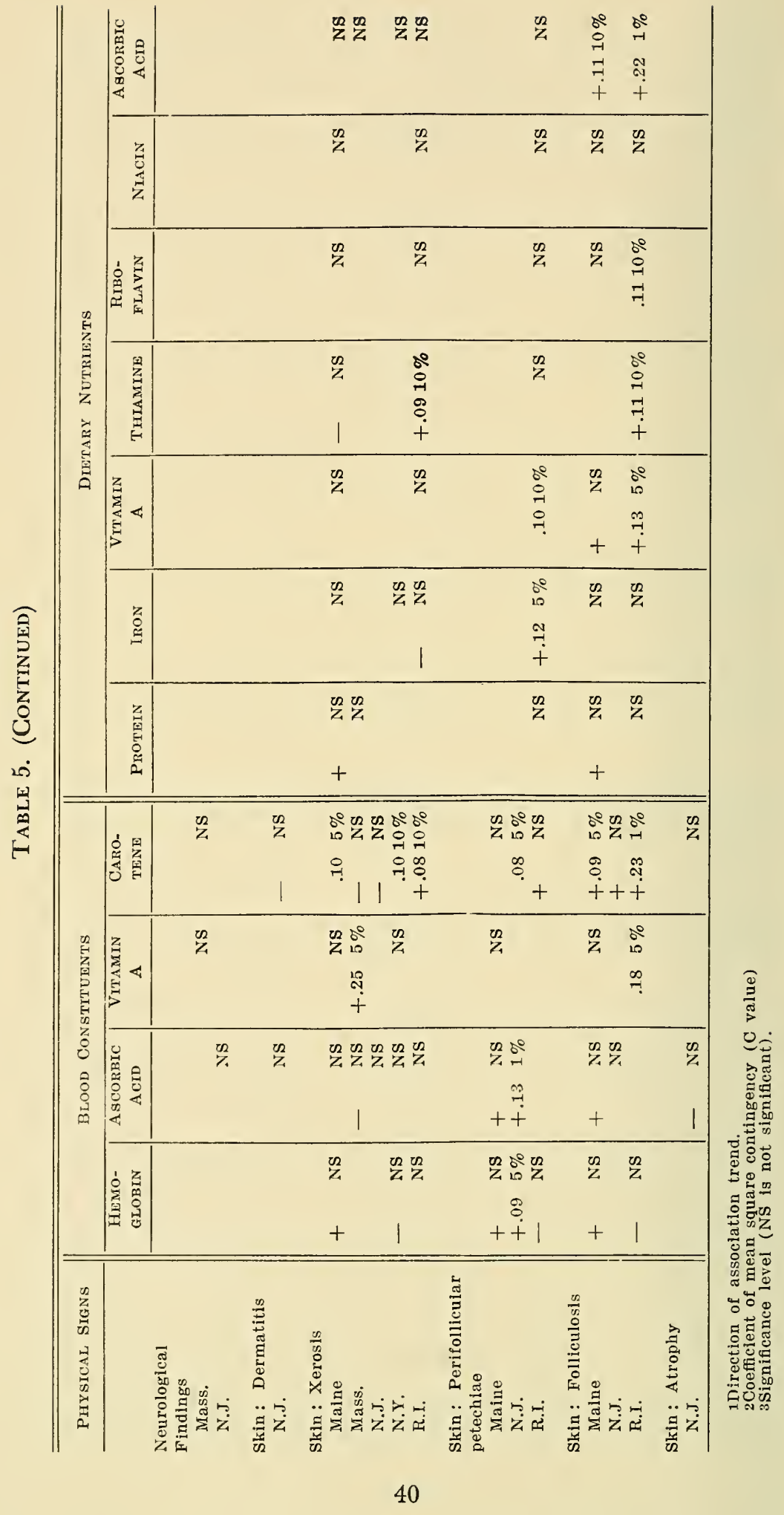




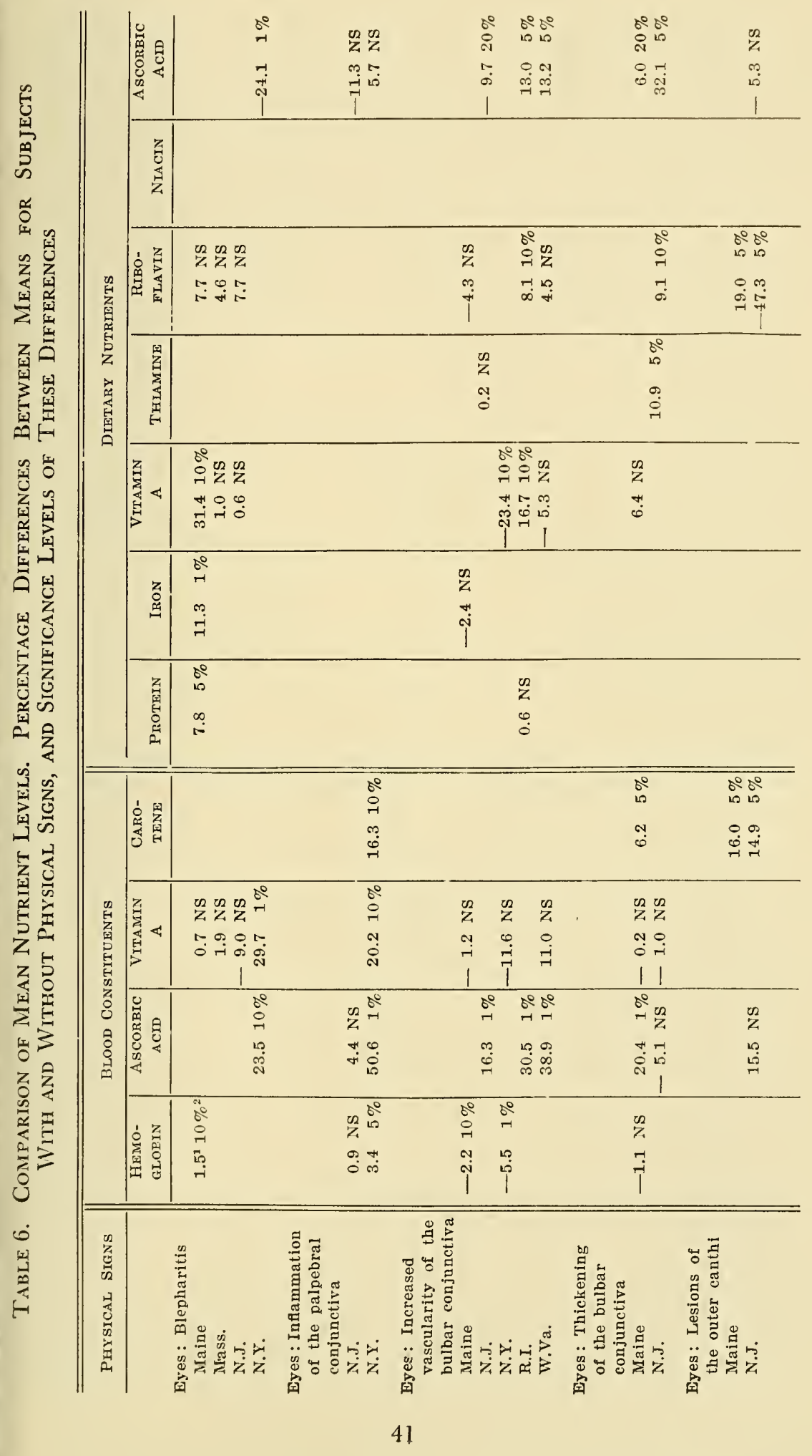




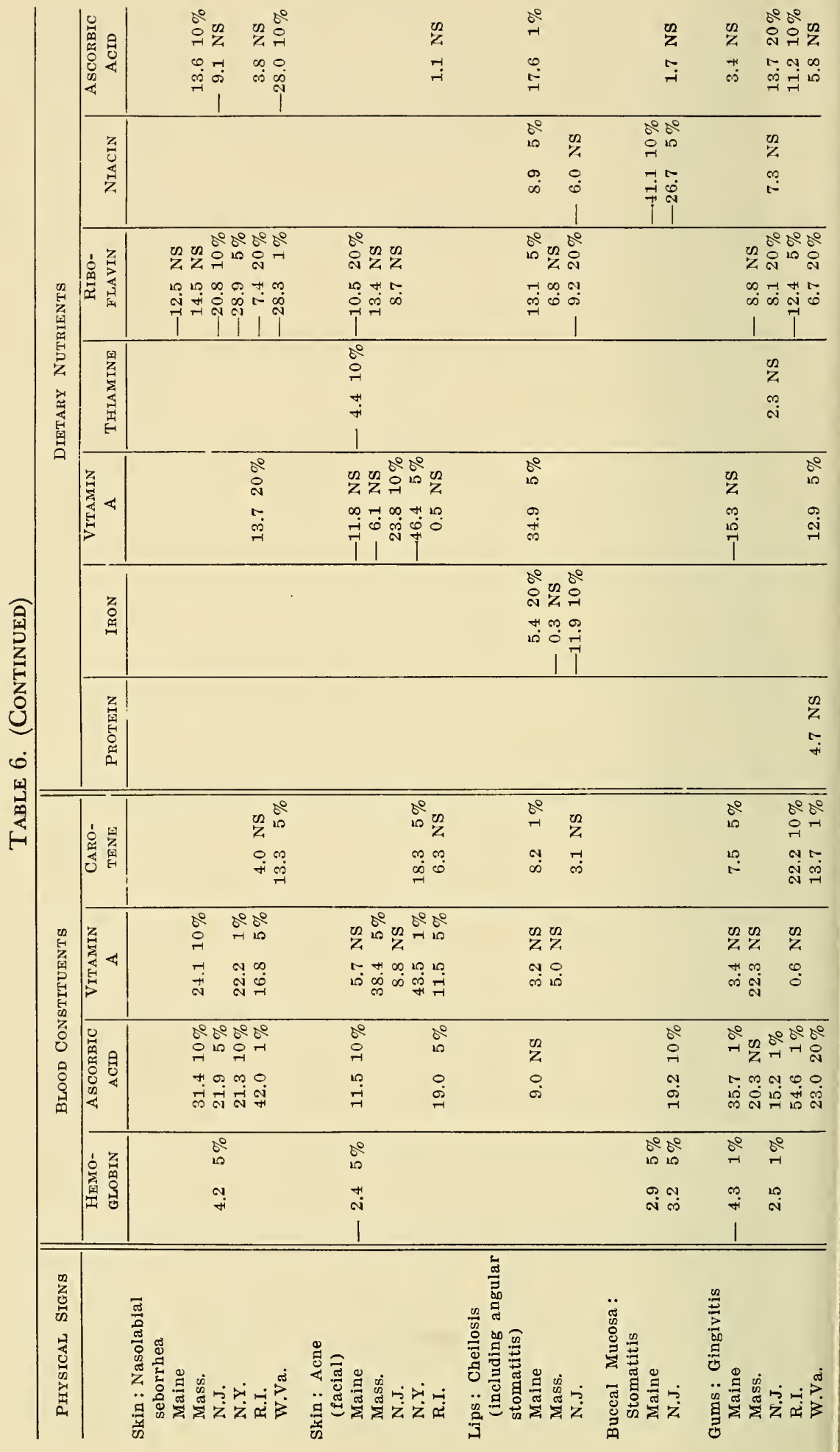



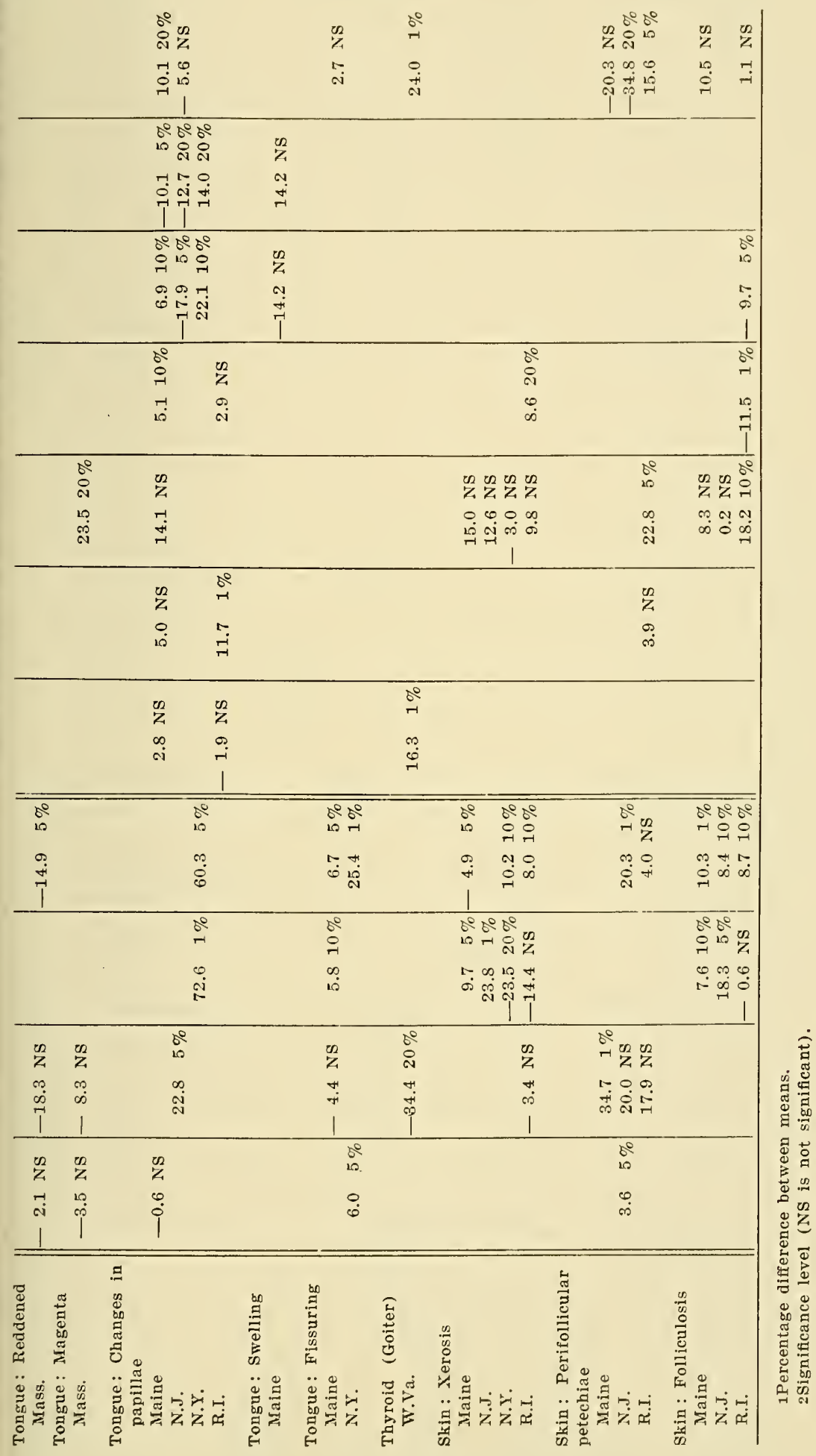


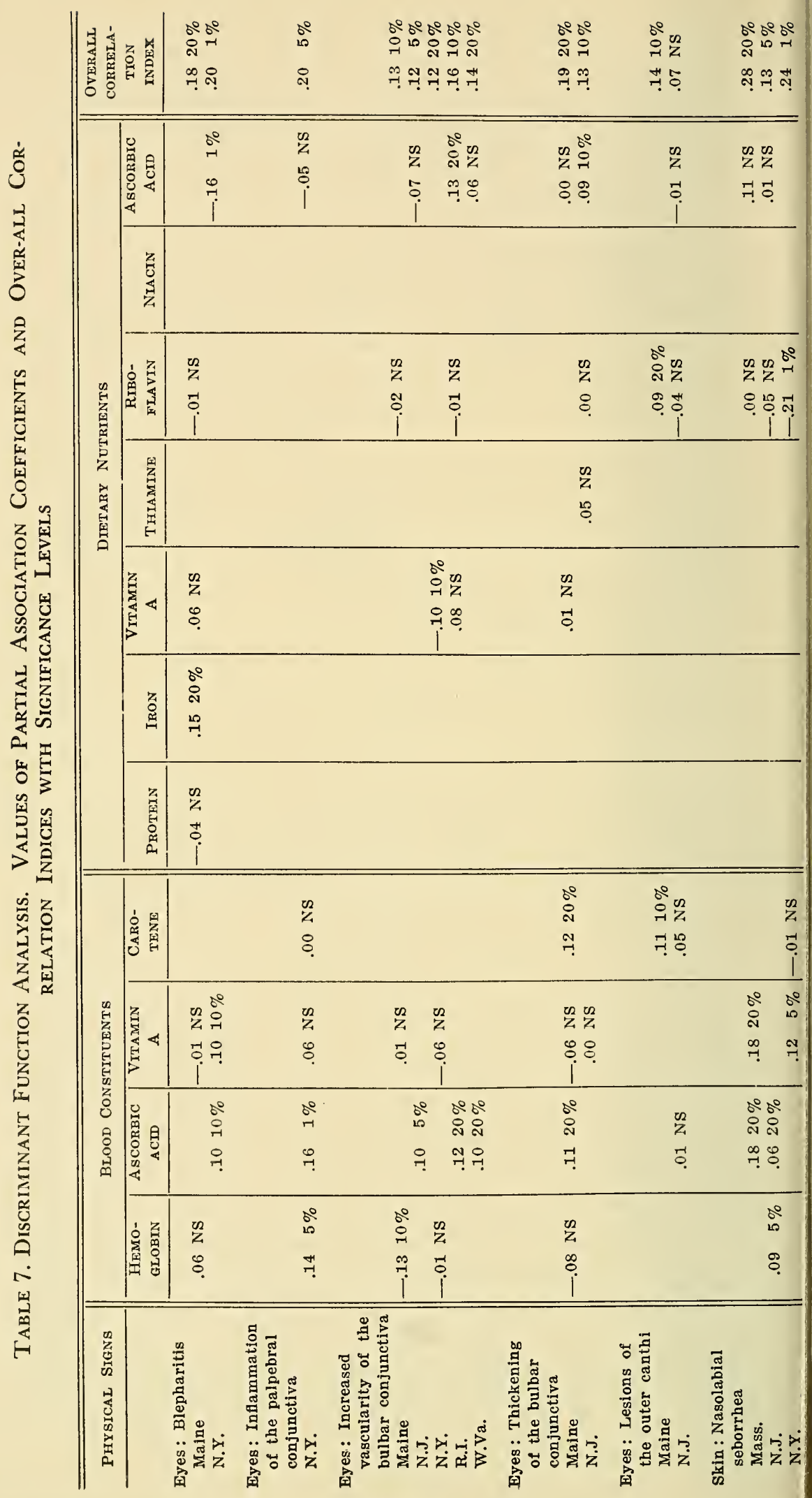




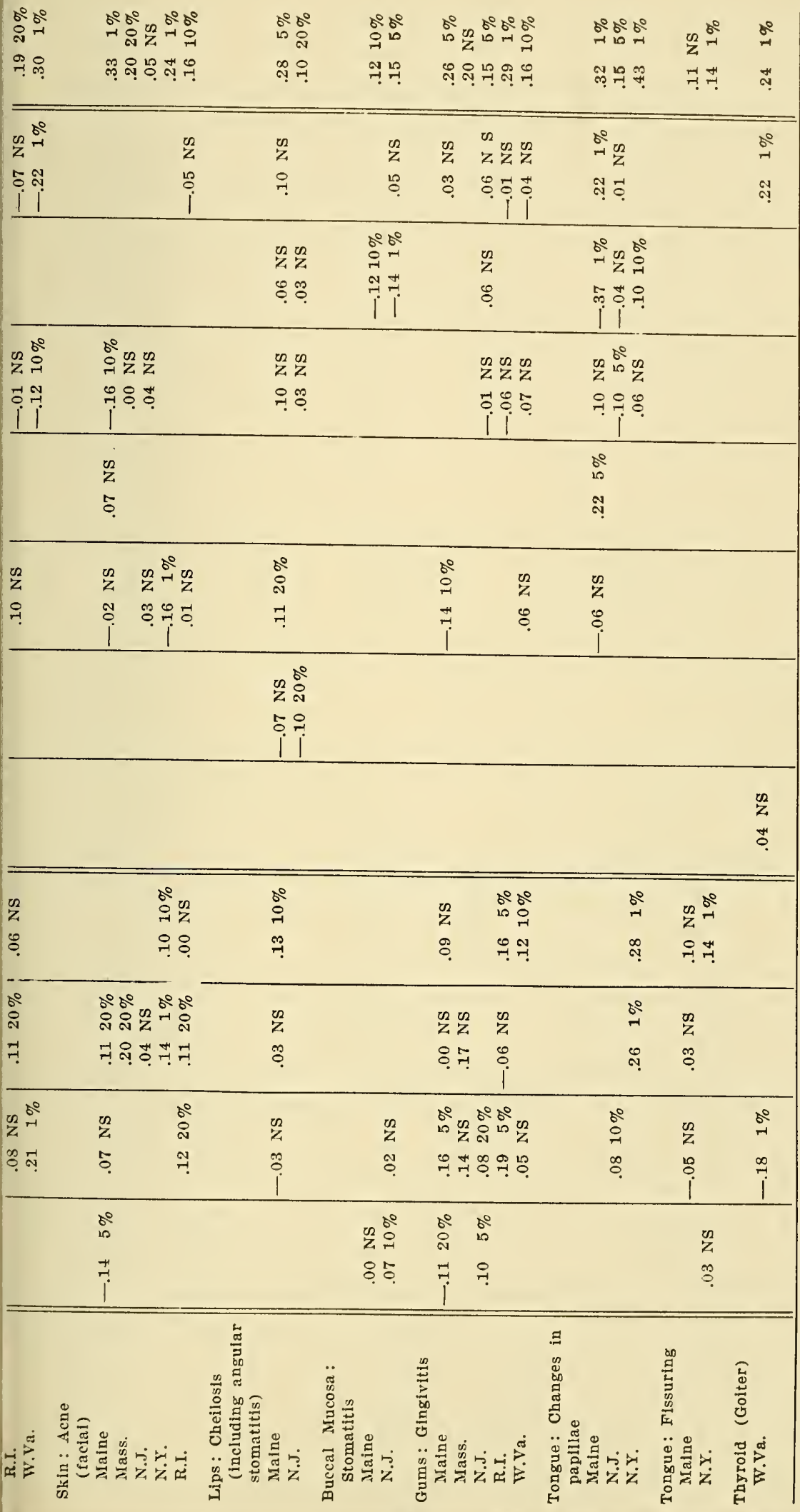




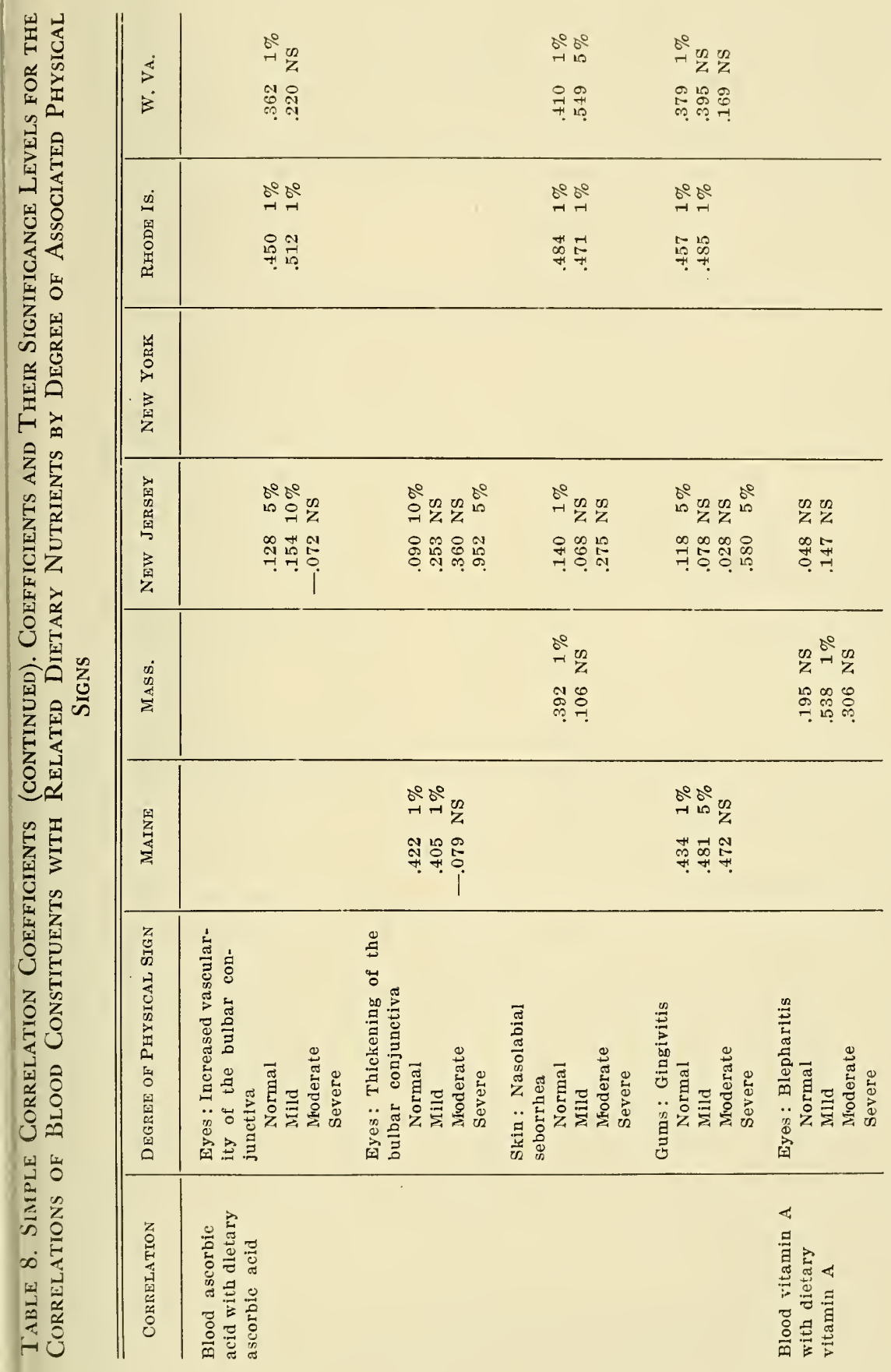




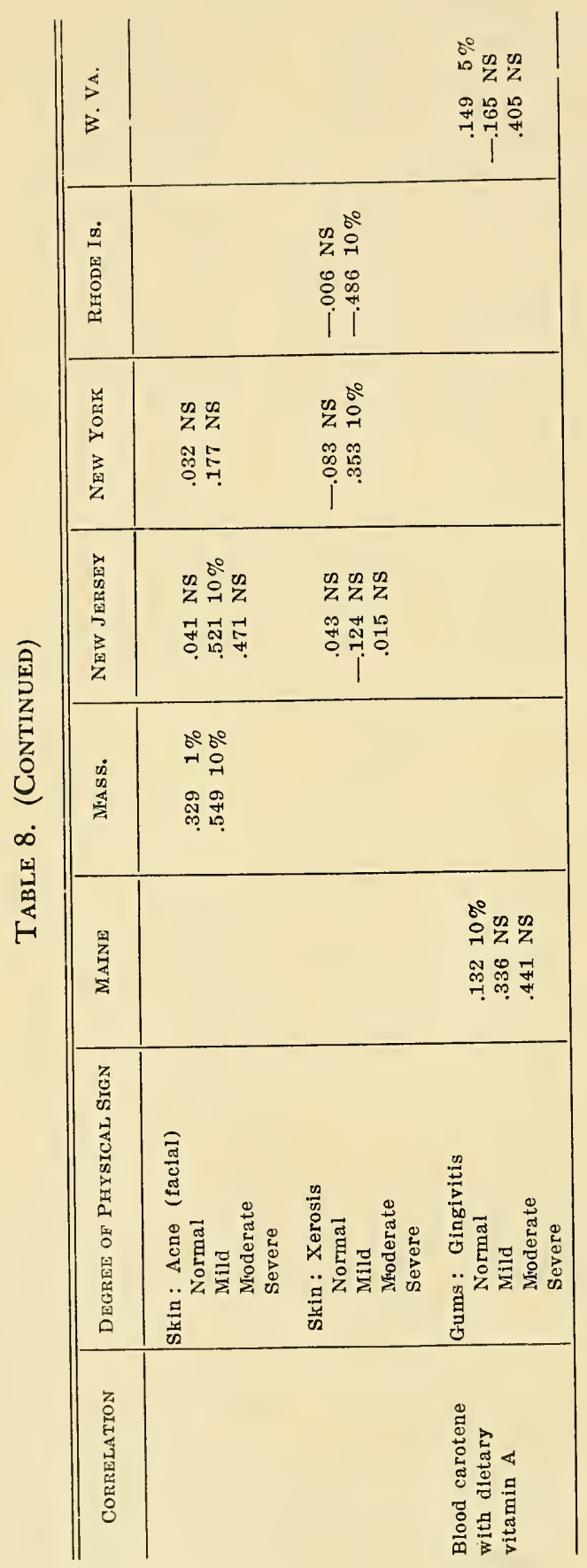



